\title{
Drivers of severe air pollution events in a deep valley during wintertime: A study case from the Arve River Valley, France.
}

\author{
Julian Quimbayo-Duarte ${ }^{a, *, 1}$, Charles Chemel $^{b}$, Chantal Staquet ${ }^{a}$, Florence Troude ${ }^{c}$ and \\ Gabriele Arduini $^{d}$ \\ ${ }^{a}$ Université Grenoble Alpes, CNRS, LEGI, F-38000, Grenoble, France \\ ${ }^{b}$ National Centre for Atmospheric Science, Centre for Atmospheric and Instrumentation Research, University of Hertfordshire, College Lane, Hatfield, \\ ALIO $9 A B, U K$ \\ ${ }^{c}$ Atmo Auvergne-Rhône-Alpes, 3 allée des Sorbiers, 69500 Bron, France \\ ${ }^{d}$ European Centre for Medium-Range Weather Forecasts, Reading, UK
}

\section{ARTICLE INFO}

\section{Keywords:}

Wintertime

particulate air-pollution

mountain valley

numerical simulation.

\begin{abstract}
A B S TRACT
The Arve river valley airshed in the French Alps experiences particularly severe air pollution during wintertime stable atmospheric conditions associated with persistent cold-air pools. $\mathrm{PM}_{10}$ data recorded in the region indicate that the urbanized area of the central basin-shape section of the valley is generally the most polluted, with a harmful impact on the health of inhabitants. In the present work, we examine the air pollution transport potential of the Arve river valley airshed using results from high-resolution numerical simulations of a cold-air pool documented as part of the Passy-2015 field campaign. Passive tracers were used to model $\mathrm{PM}_{10}$ with emissions provided by a detailed inventory developed by the local air-quality agency. The observed differential in $\mathrm{PM}_{10}$ levels between valley sections was well captured by the numerical model and could not be explained solely by the differential in emissions. The stagnation, recirculation and ventilation potential of the airshed was evaluated spatially and temporally using integral quantities. The analysis indicated that the central basin-shape section of the valley is poorly ventilated and hence air pollution there would originate mostly from local emission sources. This stagnation zone appears to be almost decoupled from the rest of the airshed. The airshed was decomposed in separate valley sections so as to quantify the fate of the pollutants emitted within each section. Air pollution apportioned according to the contribution of emissions from the different valley sections shows that indeed the central basin-shape section is dominated by local sources. The situation was found more complex in the valley sections further downstream, where the contribution from the sum of the non-local sources can be as large as that from local sources. This study allows to identify the origin of the strong pollution in the Arve river valley, through the link between the local topography, emission sources and pollutant transport.
\end{abstract}

\section{Introduction}

During the winter season, mountainous areas are affected ${ }^{18}$ by episodes of severe air pollution. This occurs when atmo- ${ }^{19}$ spheric stability increases due to the formation of a tempera- ${ }^{20}$ ture inversion that suppresses vertical mixing in the lower at- ${ }^{21}$ mosphere (Chazette et al., 2005). Particulate pollution is of ${ }^{22}$ particular concern as it has a strong effect on human health, ${ }^{23}$ from asthma to increased risk of heart attack (Anderson et al., ${ }^{24}$ 2012), and as early as the pregnancy (Guxens et al., 2014).

The relationship between meteorology and high concentration of particulate matter (PM) in the atmosphere has been ${ }^{27}$ explored extensively in the literature. Smith et al. (2001) ${ }^{28}$ used computer-calculated trajectories of air masses together ${ }^{29}$ with relevant meteorological data to interpret a three-year- ${ }^{30}$ long data set (1995-1997) of $\mathrm{PM}_{10}$ (particles with an aero- ${ }_{32}{ }^{31}$ dynamic diameter less than $10 \mu \mathrm{m}$ ) collected in London in ${ }_{33}^{32}$

^ Present address: Institut für Atmosphäre und Umwelt Goethe- 34 Universität Frankfurt am Main Altenhöferallee 1, 60438 Frankfurt/Main, 35 Germany.

quimbayo-duarte@iau.uni-frankfurt.de (J. Quimbayo-Duarte); c. chemel@herts.ac.uk (C. Chemel);

chantal.staquet@univ-grenoble-alpes.fr (C. Staquet);

ftroude@atmo-aura.fr (F. Troude); Gabriele.Arduini@ecmwf.int (G. Arduini)

$\operatorname{ORCID}(\mathrm{s})$ :

8

de describe well 60 to $65 \%$ of the observed variation of $\mathrm{PM}_{10}$
in this time period. It was concluded from this study that the local climate is not the main driver of concentration peaks; in fact, an advection of $\mathrm{PM}_{10}$ from external sources was shown to play an important role by adding in some cases up to $20 \mu \mathrm{g}$ $\mathrm{m}^{-3}$ to the concentration recorded in the city. Vardoulakis and Kassomenos (2008) analyzed a three-year-long data set (2001-2003) to explore the relationship between concentrations of $\mathrm{PM}_{10}$, other pollutants (such as carbon monoxyde and nitrogen oxydes) and meteorological variables in two European cities (Athens, Greece and Birmingham, UK). The authors found a positive correlation during the cold season between $\mathrm{PM}_{10}$ concentration, low wind speed and solar radiation, which are normally associated with stable boundary layers.

The impact of stable layers on air quality in complex terrain is well known to be more significant than over flat regions. Topographic effects lead to stronger and deeper tem36 perature inversions that block vertical ventilation and prevent mixing of pollutants which is known as cold air pools. The later may results in long periods of poor air quality and fog, depending on the sources of pollution and the amount of air humidity, respectively. In the urbanized Salt Lake valley (Utah, USA) for example, Whiteman et al. (2014) studied 
the relationship between local weather conditions and partic- 99 ulate air pollution in the winter season using a 40-year-longroo data set (1973-2003). $\mathrm{PM}_{10}$ concentrations in the area wereio1 found to be highly correlated with the valley heat deficit,02 a measure of atmospheric stability, especially on days witho3 snow-covered surface, low clouds and fog, which are ofteno4 associated with persistent (long-lasting) pollution episodes 105 Neemann et al. (2015) investigated the relationship between the development of a cold air pool and high concentrations of pollutants in the Uintah Basin, Utah, USA, for a one-week 108 long pollution episode in February 2013. Numerical modehos results showed a high sensitivity of boundary-layer develop 110 ment and ozone concentrations to snow cover. By increasing 11 surface albedo and reducing short-wave radiation absorbed ${ }_{12}$ by the surface, snow cover leads to a colder air near the $\operatorname{sur}_{113}$ face and a more stable boundary layer, leading to higher $\operatorname{con}_{114}$ centrations of pollutants. Largeron and Staquet (2016) in ${ }_{115}$ vestigated the relationship between the dynamics of persis 116 tent cold air pools (PCAPs) and episodes of high particulate 17 pollution during the winter of 2006-2007 in the Grenoble 18 valley in the northern French Alps using data from ground ${ }_{119}$ based weather and air quality stations (the acronym AQS wilhzo be used when more convenient). A criterion based solely on ${ }_{21}$ the temperature difference between the valley floor and the 22 valley top was developed to detect episodes associated with.23 persistent temperature inversions in this deep valley. Nine 24 episodes were identified during the winter, all being associ-125 ated with high particulate pollution mainly due to local emis 126 sions. Only one pollution episode during that winter was noti27 related to a temperature inversion, pollution concentration ${ }_{28}$ being due to long-range transport.

All previous studies indicate that the strength and $\mathrm{du}_{130}$ ration of wintertime temperature inversions in complex ter ${ }_{131}$ rain control the local concentration of pollutants. The deter ${ }_{132}$ mination of the resulting spatial and temporal distribution ${ }_{33}$ also requires the knowledge of the rate and location of locah 34 emission sources (as well as atmospheric chemistry). In the ${ }_{35}$ present study we focus our attention on the Arve river valley,36 located in the northern French Alps (see Fig. 1). This valley 137 has experienced high levels of particulate air pollution $\operatorname{dur}_{138}$ ing PCAPs events in the winter season since $\mathrm{PM}_{10}$ concen-139 tration is recorded (Piot, 2011), in the sense that European 4 o standards set by the Directive 2008/50/EU are exceeded (that 41 is, more than 35 days a year display a daily average value of in2 $_{2}$ $\mathrm{PM}_{10}$ concentration greater than $50 \mu \mathrm{gr} \mathrm{m}^{-3}$ ). The smalh43 town of Passy in the Arve river valley, with about $11000_{44}$ inhabitants, is one of the main concerns of local authoritiesi45 (Atmo-Auvergne-Rhône-Alpes, 2018).

During the winter of 2014-2015, a field campaign was 47 conducted around the town of Passy (Staquet et al., 2015, 148 Paci et al., 2017). The main objective of this field campaign,, 49 named Passy-2015, was to characterize the atmospheric dy 150 namics in this section of the Arve river valley and to relate ${ }_{51}$ these dynamics to pollution episodes. A strongly polluted 52 PCAP event occurred between 6 and 13 February, which wasis3 associated with the first intensive observation period (IOP1) 154 of the field campaign. Using data of this IOP1, Chemehs5 et al. (2016) explored the relationship between the temporal variability of $\mathrm{PM}_{10}$ concentration and that of the valley heat deficit. When daily-averaged values are considered, the authors found that the determination coefficient (square of the correlation coefficient) between the valley heat deficit and the $\mathrm{PM}_{10}$ concentration was high and equal to 0.69. However, the hourly evolution of the $\mathrm{PM}_{10}$ concentration was found to be relatively complex and could not be explained simply by the hourly variability of the heat deficit of the valley. The concentration of $\mathrm{PM}_{10}$ in the lower atmosphere is affected by variables such as local emissions of $\mathrm{PM}_{10}$ and local dynamics at the position where the measurement is made. An analysis of local atmospheric circulation was performed by Sabatier et al. (2018) for a section of the Arve river valley using data from a Doppler Lidar during IOP1. The authors attempted to explain the high levels of $\mathrm{PM}_{10}$ recorded and the rather special spatial distribution of pollutants along the valley during this episode. As expected, the atmospheric dynamics during the episode were characterized by a strong temperature inversion together with calm winds that prevented the ventilation of pollution out of the valley. In fact, light winds favored the formation of hot spots of high $\mathrm{PM}_{10}$ concentration, highlighting the important role of local wind dynamics in the valley. Both studies provided important insights in the understanding of the severe pollution episodes recorded in this section of the valley but also pointed out the need for numerical simulations to better understand this complex situation.

Arduini et al. (2020) used results from high-resolution numerical simulations to explore the local and non-local meteorological drivers of the PCAP event associated with IOP1. The authors analyzed the different stages of the event and pointed out the importance of the tributary valleys during the persistent stage of the PCAP, which together with the advection of air from above determine the height of the inversion layer. Throughout the episode, local and non-local interactions took place between the dynamics in the valley, the flows in and out of its main tributaries and the synoptic flow. This work provided a detailed account of the atmospheric dynamics during the PCAP event, which as shown in other studies (e.g., Silcox et al. 2012, Green et al. 2015, Baasandorj et al. 2017), have a determinant role in the accumulation of pollutants in complex terrain. However, the origin of the pollution episodes and the horizontal heterogeneity in the distribution of pollution in the valley remain outstanding issues.

The present work relies on numerical simulations of IOP1 of the Passy-2015 field campaign to study the drivers of particulate air pollution in the section of the Arve river valley near Passy. For this purpose a configuration similar to that presented in Arduini et al. (2020) is used, in which the emission inventory developed by the local air quality agency is implemented. The numerical model and the emission inventory are described in Sect. 2. In Sect. 3 the temperature and velocity fields and the $\mathrm{PM}_{10}$ concentration in the valley atmosphere as computed by the model are compared to data from the field campaign and recorded at the air quality 

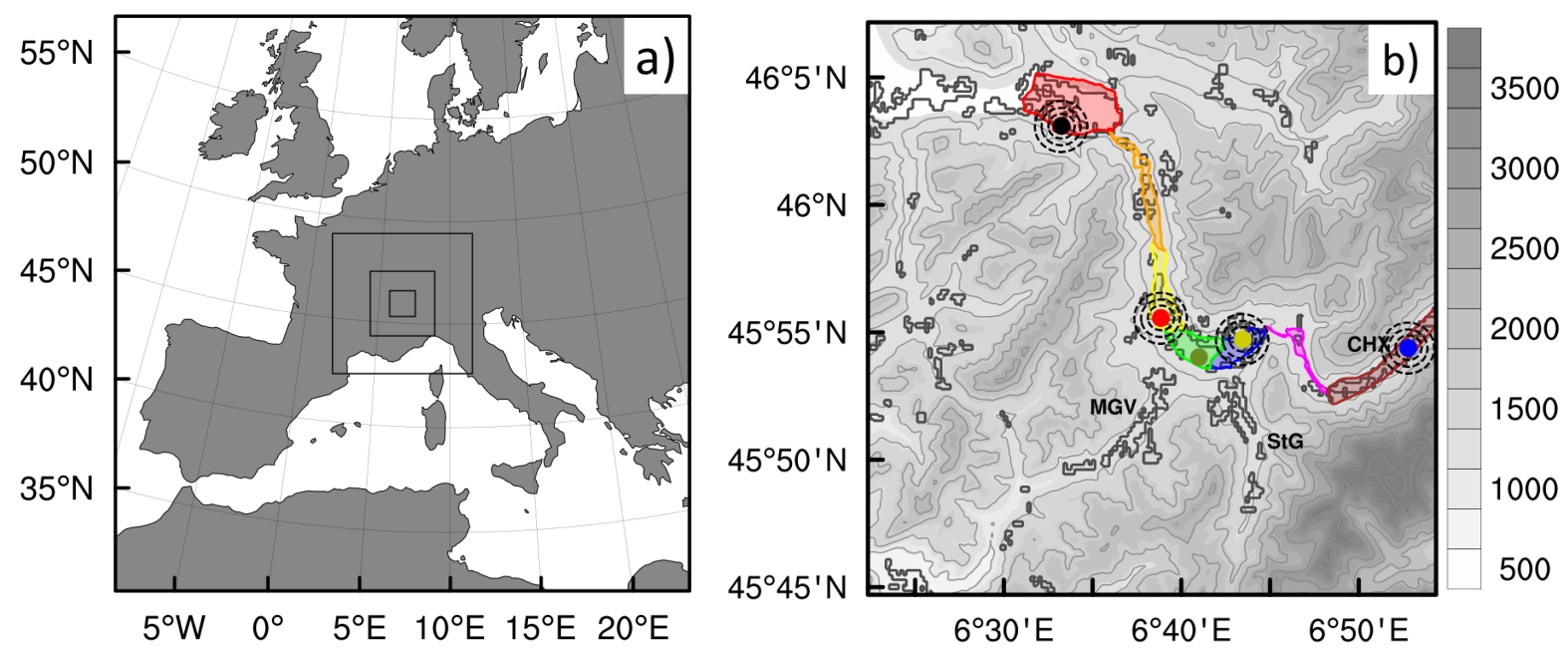

Figure 1: Domains d01, d02, d03 and d04 used in the numerical modelling of the Arve river valley (domains d02 to d04 are indicated with boxes). b) Topographical representation of the innermost domain d05. Black contours indicate urban areas in the domain. The locations of the air quality stations in the zone are marked with color dots: Chamonix (blue), Passy (yellow), Sallanches (red) and Marnaz (black). The exact locations of the stations are documented in Table 3. The location of the main measurement site in the Passy-15 field campaign is denoted with the green dot. The black letters indicate the main tributaries leading to the cities of Megève (MGV) and Saint-Gervais-les-Bains (StG). The Passy valley defined in the text is decomposed here into seven color areas, to facilitate the analysis (see section 4).

stations, respectively. The spatial distribution of $\mathrm{PM}_{10}$ con-186 centration in the valley predicted by the numerical model isis7 presented in Sect. 4. The origin of this distribution is re-188 lated to stagnation and ventilation zones computed in Sect ${ }_{189}$ 5. The local and non local contributions to pollution in each air quality station are analyzed in Sect. 6. Finally, conclu 191 sions along with a discussion are presented in Sect. $7 . \quad 192$

\section{The numerical model}

\subsection{The Passy valley}

The Arve valley is located in the north of the French Alps, near the French-Swiss border (see Fig. 1). In the $\mathbf{1}_{\mathbf{1 9 8}}$ present paper, we focus on the section of the valley near ${ }_{199}$ Passy, named the Passy valley as in Arduini et al. (2020) ${\text { ( } \text { see }_{200}}$ Fig. 1b). This valley section involves three other cities, $\mathrm{Sal}_{-201}$ lanches (16,700 inhabitants) and Marnaz (5,500 inhabitants) ${ }_{202}$ located downstream of Passy, and Chamonix $\left(8,900\right.$ inhab- $_{203}$ itants) located upstream. The altitude of the valley floor in ${ }_{204}$ Passy is about $560 \mathrm{~m}$ above sea level (a.s.1.). It decreases ${ }_{205}$ downstream along the $24 \mathrm{~km}$ length of the valley to $475 \mathrm{~m}_{206}$ a.s.l. in Marnaz and increases upstream through a steep sill ${ }_{207}$ with slope about $10^{\circ}$, to Chamonix, which is distant from ${ }_{208}$ Passy by $20 \mathrm{~km}$ and of altitude $1035 \mathrm{~m}$. The Passy valley is ${ }_{209}$ surrounded by high mountains that reach up to $2,700 \mathrm{~m}$ a.s. $1_{\mathbf{2 1 0}}$ in the western and northern parts of the valley. The highest ${ }_{211}$ peak in the area is Mont Blanc (4808 $\mathrm{m}$ a.s.1.), located right ${ }_{212}$ above and south of the town of Chamonix. The Passy valley ${ }_{213}$ has two main tributaries leading to the cities of Megève and ${ }_{214}$ Saint-Gervais-les-Bains (see Fig. 1b). In the winter season ${ }_{215}$ the local time (LT) is UTC+1 (Coordinated Universal Time (16 $_{216}$ plus one hour). All times below are expressed in local time.

\subsection{Configuration of the meteorological model}

The Weather Research and Forecasting (WRF) model (Skamarock et al., 2005), version 3.5.1, was used to perform the numerical simulations, and customized as described below. The model was coupled to a chemical module (WRFChem) to model the diffusion and transport processes of passive tracers emulating the behavior of $\mathrm{PM}_{10}$ in the atmosphere. In this work, we assume indeed that $\mathrm{PM}_{10}$ has a low chemical reactivity during wintertime conditions and can be modelled as a passive tracer. Elemental carbon (EC), which represents a significant fraction of the total mass of $\mathrm{PM}_{10}$ in winter (up to $15 \%$, Aymoz et al. 2007) is actually well known for its low chemical reactivity in the atmosphere.

The simulation was performed using five nested domains centered in the airport of Sallanches $\left(45.935^{\circ} \mathrm{N}, 6.636^{\circ} \mathrm{E}\right)$ and was carried out in three steps. The first three domains (d01, d02 and d03) were run in a one-way online nested configuration, covering the continental scales (see Fig. 1a). Reanalysed data from the European Centre for Medium-Range Meteorological Forecasts (ECMWF) were used to initialize the model and provide the lateral boundary conditions for the outermost domain with a 6-hour update. The simulation started on 7 February 2015 at 1300 LT and was run for 7 days until 14 February 2015 at 1300 LT. The size, horizontal and vertical resolutions and time step for each domain are listed in Table 1.

In a second step, the results obtained for domain $\mathrm{d} 03$ were used as initial and lateral boundary conditions for domain d04 through a down-scaling process. The lateral boundaries of domain d04 were updated every 10 minutes. This simulation for domain d04 was run for six days, from 8 Febru- 
ary at $1300 \mathrm{LT}$ to 14 February at $1300 \mathrm{LT}$.

Finally, the same downscaling method was applied toe6o produce the initial and lateral boundary conditions for do-261 main $\mathrm{d} 05$, in which the horizontal resolution of the grid is 62 $111 \mathrm{~m}$ in the horizontal and 92 grid points are used in the 263 vertical direction. The vertical coordinate was stretched So264 as to refine the resolution near the ground, with the first grick65 point located at $9.2 \mathrm{~m}$ above ground (implying that the firster6 mass point is at $4.6 \mathrm{~m}$ ). The simulation for domain d05 was267 run from 9 February at 1300 LT to 13 February at 1300 LT. 268

\begin{tabular}{|c|c|c|c|c|c|}
\hline Domain & $n x, n y, n z$ & $\Delta x=\Delta y$ & $\Delta z_{\min }$ & $\Delta t$ & 270 \\
\hline $\mathrm{d} 01$ & $202,202,46$ & $15 \mathrm{~km}$ & $42 \mathrm{~m}$ & $30 \mathrm{~s}$ & 271 \\
$\mathrm{~d} 02$ & $246,246,46$ & $3 \mathrm{~km}$ & $42 \mathrm{~m}$ & $6 \mathrm{~s}$ & 272 \\
$\mathrm{~d} 03$ & $340,340,46$ & $1 \mathrm{~km}$ & $42 \mathrm{~m}$ & $2 \mathrm{~s}$ & 273 \\
$\mathrm{~d} 04$ & $406,406,92$ & $333 \mathrm{~m}$ & $21 \mathrm{~m}$ & $0.6 \mathrm{~s}$ & 274 \\
$\mathrm{~d} 05$ & $382,382,92$ & $111 \mathrm{~m}$ & $9.2 \mathrm{~m}$ & $0.06 \mathrm{~s}$ & 275 \\
\end{tabular}

Table 1: Main parameters used in the simulations. The num- ${ }^{276}$ ber of grid points $n x, n y, n z$ correspond to the east-west ${ }_{278}^{277}$ north-south and vertical directions, respectively. The vertical coordinate is stretched with height and $\Delta z_{\min }$ represents $_{279}$ the height above the ground of the first grid point, the first ${ }_{280}$ mass point being located at $\Delta z_{\min } / 2$.

The planetary boundary layer (PBL) was parameterize ${ }^{282}$ in the first online run (for $\mathrm{d} 01, \mathrm{~d} 02$ and d03) using the $\mathrm{Yon}_{-284}$ sei University (YSU) scheme (Hong, 2010). For the two in- ${ }_{285}$ nermost domains (d04 and d05), the PBL was explicitly re- ${ }_{286}$ solved using a turbulent kinetic energy (TKE) 1.5 order clo- $_{287}$ sure employing a Smagorinsky coefficient $\mathrm{C}_{S}$ equal to $0.1_{288}$ The other physical and dynamical options were the same ${ }_{289}$ in all domains. The temporal discretization of the $\operatorname{model}_{290}$ equations is based on a Runge-Kutta scheme of third order $_{291}$ and a time-splitting technique is implemented for the acous- ${ }_{292}$ tic modes. The advection terms were discretized using $\mathrm{a}_{293}$ fifth-order Weighted Essentially Non-Oscillatory (WENO) scheme with positive definite filter. The scheme developed ${ }_{295}$ by Morrison et al. (2005) was used to parametrize the mi $^{296}$ crophysics in the model with the inclusion of the modifica- ${ }_{297}$ tions on the treatment of ice fog proposed by Neemann et $\mathrm{al}_{298}$ (2015). Shortwave and longwave radiation were parameter- ${ }_{299}$ ized with the Rapid Radiative Transfer Model (Mlawer et al. ${ }_{300}$ 1997). Land-surface processes were modelled with the $\mathrm{Noah}_{301}$ land surface model with four soil layers (Chen and Dudhia ${ }_{302}$ 2001) and the ground thermal conductivity and the latent ${ }_{303}$ heat flux as computed in the WRF model version 3.7 were $_{304}$ implemented. The surface layer physics was modelled by ${ }_{305}$ the revised MM5 Monin-Obukhov scheme (Jiménez et al. 2012).

\subsection{Terrain representation in the numerical model}

DData from the Shuttle Radar Topography Mission (Fa et al., 2007) at a resolution of about $90 \mathrm{~m}$ were used to $\mathrm{cre}_{312}^{311}$ ate the topography, which was interpolated to the horizontal ${ }_{313}$ resolution of the d01 to d05 domains. For a horizontal resolution of $3 \mathrm{~km}(\mathrm{~d} 02)$, the maximum slope angle of the terrain is about $25^{\circ}$ but for a $100 \mathrm{~m}$ resolution (d05), this maximum slope can reach values close to $75^{\circ}$. Such a steep slope generates numerical instability and a filter was implemented in the model to reduce the maximum slope angle to $42^{\circ}$ to overcome this problem. The general shape of the topography is retained while maintaining the main small-scale characteristics of the topography.

Due to the importance of snow cover in surface-atmosphere interactions (Tomasi et al. 2014; Neemann et al. 2015), a method was developed for the initialization of snow cover in the model. Indeed, the resolution of currently available numerical model reanalysis products is about $15 \mathrm{~km}$, a too coarse resolution for an adequate representation of the snow layer during the simulated days in the d05 domain. In the present work, MODIS/Terra (MOD10_L2) satellite products for snow cover at a spatial resolution of $500 \mathrm{~m}$ were averaged between 5 and 10 February 2015 and interpolated at the horizontal resolution of the innermost domain to initialize the snow fields. The initialization of the snow albedo and snow depth is described in Arduini et al. (2020).

\subsection{Emission Input}

The emission input used in the simulations is based on an emission inventory developed by the local air quality agency of the Auvergne Rhône-Alpes region (Atmo-Aura) for the year 2015 (Atmo-Auvergne-Rhône-Alpes, 2017). The inventory is available at a resolution of $100 \mathrm{~m}$ in the whole region and was implemented in domain d05 of the simulations only. The inventory involves several pollutants, such as nitrogen oxides, non-metallic volatile organic compounds, polycyclic aromatic hydrocarbons, heavy metals and suspended particles such as $\mathrm{PM}_{10}$ which are the focus of the present work.

The different emission sectors are categorised using the classification proposed by the European Topic Centre on Atmospheric Emissions (ETC/AE), which classifies the activities generating an emission of pollutants into the atmosphere using the Selected Nomenclature of Air Pollution Sources (SNAP). The eleven SNAP categories, or sectors as commonly named, have been considered and their contribution to the total emission of $\mathrm{PM}_{10}$ in domain $\mathrm{d} 05$ is presented in Table 2. The table shows that in this area three main contributors account for about $90 \%$ of the total emissions: residential heating (SNAP 2), production processes (SNAP 4) and road transport (SNAP 7), contributing 61.24\%, 9.55\% and $19.42 \%$, respectively. The former value is consistent with the finding of Chevrier (2016) that biomass burning averaged over the winter of 2013-2014 contributes between $62 \%$ and $73 \%$ to $\mathrm{PM}_{10}$ concentration when recorded at the air quality stations of the Passy valley. Note that emissions from SNAP 7 sector in Table 2 are limited to the valley core, from Marnaz to Passy, due to missing data in the original emission inventory. Estimating these missing data yields a corrected mass contribution of $23.5 \%$, which is close to the value reported in Table 2 .

Because the emission inventory is provided as the total mass emitted for the whole year, a disaggregation of the to- 
Drivers of severe air pollution events in a deep valley during wintertime

\begin{tabular}{|c|l|c|}
\hline SNAP & \multicolumn{1}{|c|}{ Classification } & \% in mass \\
\hline 1 & Combustion in energy and transformation industries & 1,28 \\
2 & Non-industrial combustion plants (Residential heating) & 61,24 \\
3 & Combustion in manufacturing industry & 2,56 \\
4 & Production processes & 9,55 \\
5 & Extraction and distribution of fossil fuels and geothermal energy & 0,00 \\
6 & Solvent and other product use & 0,75 \\
7 & Road transport & 19,42 \\
8 & Other mobile sources & 3,03 \\
9 & Waste treatment and disposal & 0,97 \\
10 & Agriculture & 1,20 \\
11 & Other sources and sinks & 0,00 \\
\hline
\end{tabular}

Table 2: The relative mass contribution of each SNAP sector to the total $\mathrm{PM}_{10}$ emission in the innermost numerical domain d05 as provided by the emission inventory supplied by Atmo-Aura for the year 2015. Note that emission from SNAP sector 7 is limited to the central part of the Passy valley, from Marnaz to Passy. (An estimate of the missing emissions, which are mainly contributed by the Chamonix area and Megève valley, yields a relative contribution of the total mass in SNAP sector 7 of about $23.5 \%$.)

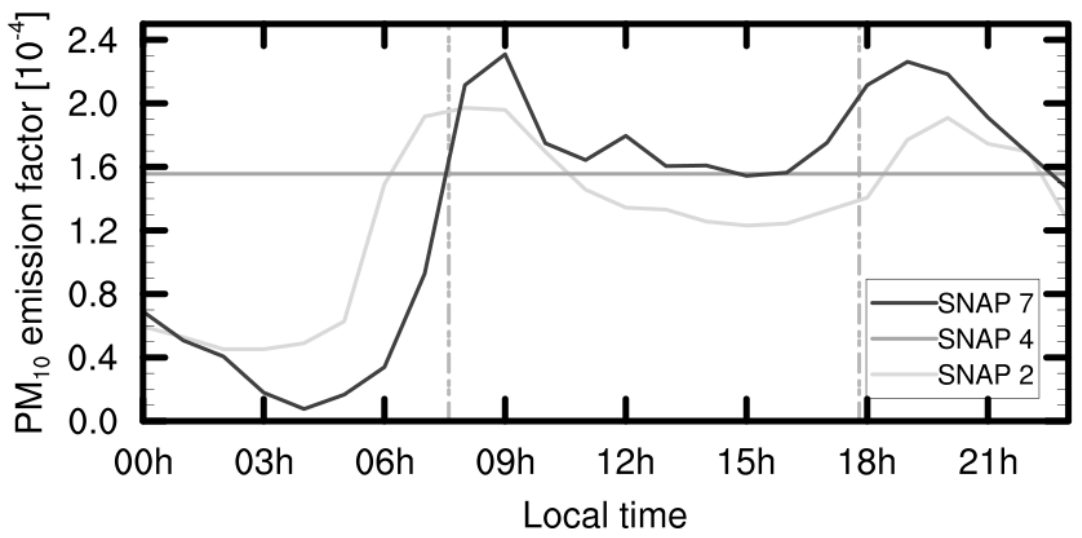

Figure 2: First level disaggregation in time of total year emission for a complete daily cycle during the first week of February 2015 for the three main SNAP sectors emitting in the area, SNAP 2 (residential heating, light grey line), SNAP 4 (production processes, dark grey line) and SNAP 7 (route transport, black line). Vertical dashed lines stands for the average sunrise and sunset times during the simulation period.

tal value must be made for each simulated day. For this pur-334 pose, a daily temporal profile of emission factors is used, ${ }_{335}$ which depends upon the SNAP sector (among other factors,336 see Atmo-Auvergne-Rhône-Alpes, 2017). Figure 2 display\$3з the daily profiles we implemented for the three main $\mathrm{SNAP}_{338}$ sectors represented in this area (SNAP 2, SNAP4 and SNAP ${ }_{339}$ 7), based upon the recommendations of Atmo-Aura (Atmo-340 Auvergne-Rhône-Alpes, 2017) and of the Netherlands Orga-s41 nization for Applied Scientific Research, TNO (Schaap et al., 2005). The profiles for SNAP 2 and SNAP 7 display two emission peaks which correspond to the morning and late afternoon rush hours. The morning peak of SNAP 2, due to residential heating, occurs slightly before that for SNAP 7, due to road transport, the order of occurrence of these two peaks reversing for the late afternoon rush hour. SNAP sector 4 is represented by a constant emission factor.

In the numerical model, the emission input file was created with all $\mathrm{PM}_{10}$ emissions available in domain $\mathrm{d} 05$, which is the area of interest. The WRF-Chem model read the emis- sion inputs every hour, all emissions being released at ground level. Two simulations were performed. In the first numerical experiment, serving as reference, the tracer field was forced with $\mathrm{PM}_{10}$ emissions in the whole d05 domain. In the second numerical experiment, the Arve river valley between Marnaz and Chamonix was divided into seven subsections, represented by color areas in Fig. 1b. Four areas among the seven were defined around the air quality stations

\begin{tabular}{|c|c|c|c|}
\hline Location & Latitude & Longitude & H [m .a.s.l.] \\
\hline Chamonix & $45.93^{\circ} \mathrm{N}$ & $6.87^{\circ} \mathrm{E}$ & 1038 \\
Passy & $45.92^{\circ} \mathrm{N}$ & $6.71^{\circ} \mathrm{E}$ & 588 \\
Sallanches & $45.94^{\circ} \mathrm{N}$ & $6.64^{\circ} \mathrm{E}$ & 542 \\
Marnaz & $46.06^{\circ} \mathrm{N}$ & $6.53^{\circ} \mathrm{E}$ & 504 \\
\hline
\end{tabular}

Table 3: Location of the four air-quality stations in the innermost domain $\mathrm{d} 05$. These locations are indicated with color dots in Fig. 3. 


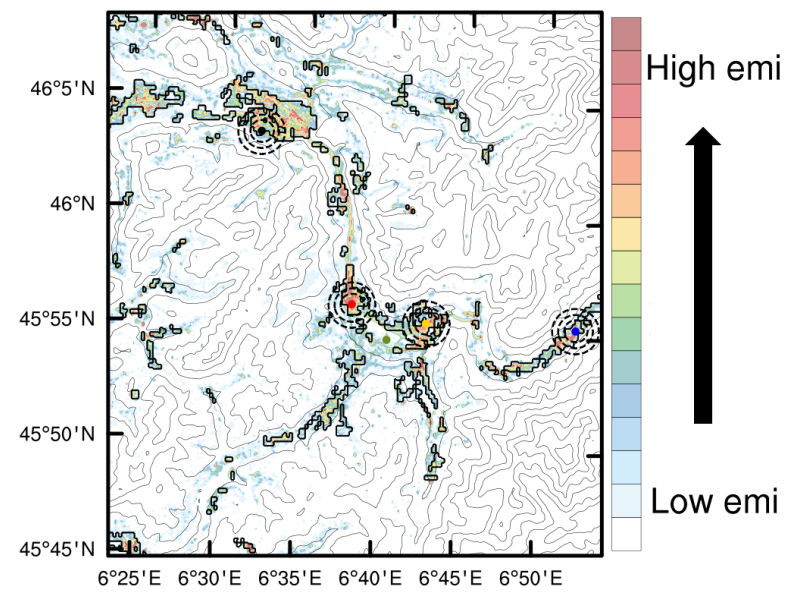
(higut $i_{386}$ the domain for a complete day (9th February 2015) overlaid $_{387}$ with contours of the terrain height (grey contours). Black ${ }_{388}$ contours indicate urban areas in the domain. The locations $s_{89}$ of the air quality stations in the zone are marked with colour $_{390}$ dots: Chamonix (blue), Passy (yellow), Sallanches (red) and ${ }_{391}$ Marnaz (black). In addition, the location of the main mea 392 surement site in the Passy-15 field campaign is denoted with ${ }_{393}$ a green dot. No scale is provided for confidentiality reasons $s_{394}$ . the
ing ings, which is equal $0.5 \mathrm{~K}$. Overall, except for the first 100
meters above the ground, we can conclude that a good agree-
ment is observed between the simulation results and the field data.

The numerical simulations presented in this paper rely on previous work by Arduini et al. (2020), as mentioned above, in which two main changes were brought. The vertical resolution was increased by almost a factor of two in the first $200 \mathrm{~m}$ above the ground level, with 15 grid points in the current configuration versus 8 in the model of Arduini et al. (2020). This aims at a better representation of the lower atmosphere, where pollutants are transported. A second difference is that in the present case the model was run continuously over the five-day period, as opposed to a reinitialization every 24 hours in the simulations by Arduini et al. (2020) (the reason being that the latter simulations were compared with idealized simulations run over successive 24hour periods).

The results of the two models are compared in Fig. 5 which displays the vertical profiles of the potential temperature (Fig. 5a and 5b) and of the wind speed (Fig. 5c and $5 \mathrm{~d})$ versus time during IOP1 at the main measurement site. The vertical profile of the MAE with respect to the field data is also displayed for each model. The wind field data have been obtained by a Lidar Windcube 8 from a height of 40 $\mathrm{m}$ above the ground (this instrument being blind below this height). Potential temperature field data have been obtained from radiosoundings, as noted above. Figure 5 displays a focus on the region close to the ground, up to $1000 \mathrm{~m}$ a.s.l., where we expect the differences between the two models, if any, to be the largest. (Figure 5a is therefore a zoom of Fig. $4 \mathrm{~b}$ from the ground to $1000 \mathrm{~m}$ ).

When the potential temperature profiles are considered (Fig. 5a and 5b), the vertical profiles of the MAE of the two simulations differ by at most $0.7 \mathrm{~K}$, and this occurs close to the ground. This difference is of the same order as the accuracy of the measurements by the radiosoundings (equal to $0.5 \mathrm{~K}$, as noted above) and is therefore not significant. Considering now the wind speed profiles, the MAE profiles for 
Drivers of severe air pollution events in a deep valley during wintertime
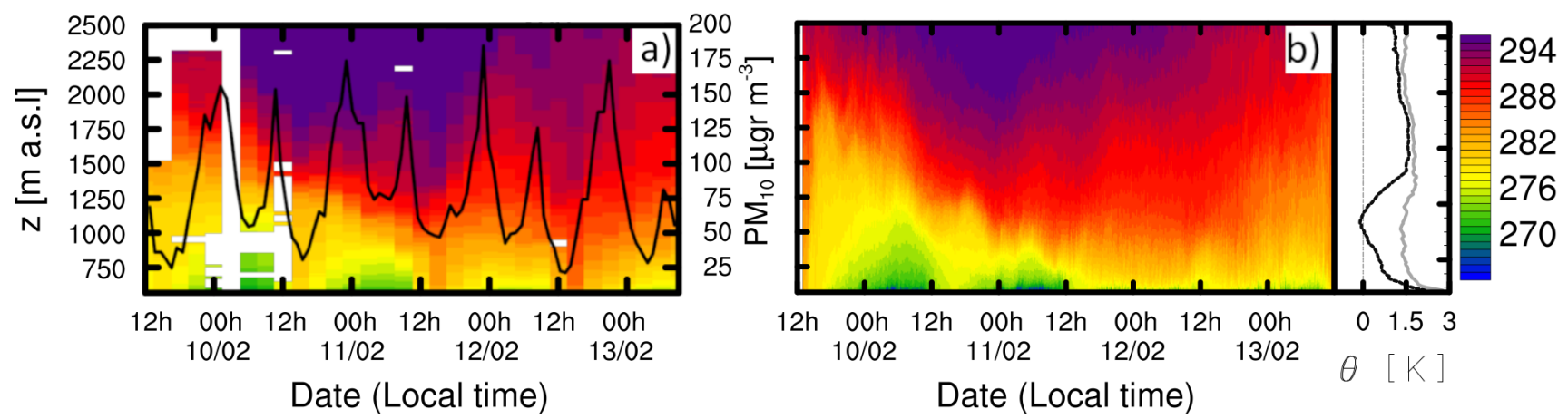

Figure 4: a) Temporal evolution of the vertical structure of the cold-air pool obtained by compiling potential temperature profiles from the radio sounding ascents performed during the Passy- 15 field campaign at the location of the main measurement (IOP site) overlaid with the $\mathrm{PM}_{10}$ concentration registered over the same time period by the air quality station at Passy (black line). b) Temporal evolution of the vertical structure of the cold-air pool by computing the potential temperature vertical profiles with the WRF model at the same location.

the two models are very similar over a height of $100 \mathrm{~m}$ above 466 the ground, the difference below that height being of at mosta67 $0.26 \mathrm{~m} \cdot \mathrm{s}^{-1}$. Since the accuracy of the LIDAR is equal tous8 $0.2 \mathrm{~m} . \mathrm{s}^{-1}$, this difference between the two models can again ${ }_{69}$ be considered as non significant. We can therefore concludea70 that the increase of the grid resolution close to the ground $\mathrm{h}_{71}$ and the continuous running of the simulation over five days472 do not bring any improvement in the comparison with the 473 field data.

The fact that the increase of the grid resolution close to475 the ground does not bring any improvement calls for other in-476 terpretations of the differences between the numerical modeh ${ }_{47}$ and the field data. Both numerical simulations display an78 warmer air temperature near the ground when compared to479 the field data (the bias in absolute value being at most $2 \mathrm{~K})_{480}$ and an overestimation of the wind speed (close to the ground $\mathbf{A 8 1}_{\mathbf{4} 1}$ the bias is positive and equal to $0.3 \mathrm{~m} . \mathrm{s}^{-1}$ at most). This $\operatorname{sug}_{-482}$ gests that the heat and moist fluxes from the soil to the atmo-483 sphere may not be well represented, as well as surface rough-484 ness elements such as forests (Chow et al., 2006, De Meij and485 Vinuesa, 2014, Foster et al., 2017, Wagner et al., 2019). It486 should also be pointed out that the effect of the $\mathrm{PM}_{10}$ pol-487 luted air on radiative transfer is not taken into in account inss the model, while this effect has been shown to reduce the 489 local air temperature and the wind speed (Nair et al., 2017)

\subsection{Numerical predictions versus measurements ${ }_{493}^{492}$ at air-quality stations}

The PCAP event observed during IOP1 was associated a $_{95}$ with a strongly polluted episode. This is attested in Fig. $4 a_{496}$ where the temporal evolution of the hourly-averaged $\mathrm{PM}_{10^{497}}$ concentration recorded at the AQS in Passy is superposed on ${ }_{498}$ the potential temperature profiles. The $\mathrm{PM}_{10}$ concentration ${ }_{99}$ exhibits two peaks per day, in the morning and at night, con-5oo sistent with the emission profile used in the simulation (seesor Fig. 2). $\mathrm{PM}_{10}$ being mainly contributed by wood burning ${ }_{502}$ (see Table 2 for SNAP2), peak values at nighttime are higherso3 than in the morning, reaching values up to $180 \mu \mathrm{gr} \mathrm{m}^{-3}$ ons04 the 11 February. The lowest values of the concentration, still comprised between 25 and $50 \mu \mathrm{gr} \mathrm{m}^{-3}$, occur around 1300 LT, as a shallow convective layer develops above the ground due to the insolation of the ground surface. In the morning of 13 February, the peak values of the previous mornings drop from a value above $120 \mu \mathrm{gr} \mathrm{m}^{-3}$ to $80 \mu \mathrm{gr} \mathrm{m}^{-3}$ due to the change in the synoptic regime and the progressive destruction of the CAP.

The purpose of this section is to assess the validity of $\mathrm{PM}_{10}$ concentration predicted by the model with respect to measurements of that concentration at the four air-quality stations located in the innermost domain. Figure 6 presents a comparison between the predicted and recorded values between 9 and 13 February 2015.

The values of the $\mathrm{PM}_{10}$ concentration recorded at the AQS display two marked peaks in the morning and at night, the morning peak being sharper and most often of lower intensity than at night. The average over the period of these recorded values is higher at the AQS in Passy, equal to 72.6 $\mu \mathrm{gr} \mathrm{m}^{-3}$, than at the AQS in Sallanches and in Chamonix, located downstream and upstream of Passy, respectively. $\mathrm{PM}_{10}$ concentrations recorded at the AQS in Marnaz, located outside the valley in a less confined area, are much lower with an average during the episode of about $30 \mu \mathrm{gr} \mathrm{m}^{-3}$.

In the upstream section of the valley in Chamonix, the model captures the temporal variation of the $\mathrm{PM}_{10}$ concentration, but it underestimates the magnitude of that concentration throughout the simulated time period (see Fig. 6a). We recall that the emission inventory in Chamonix does not include emissions of SNAP sector 7, which may contribute to the underestimation of $\mathrm{PM}_{10}$ by the numerical model in this valley section. In Passy, the magnitude and temporal variation of the $\mathrm{PM}_{10}$ concentration during the mornings are well represented (see Fig. 6b). However, the model does not capture adequately the nocturnal peaks occurring at around $0100 \mathrm{LT}$, the concentration reaching a maximum value about 4 hours too early. This point is further discussed below, in light of Fig. 7. In Sallanches, the model simulates well the $\mathrm{PM}_{10}$ concentration observed at the monitoring site, al- 
Drivers of severe air pollution events in a deep valley during wintertime
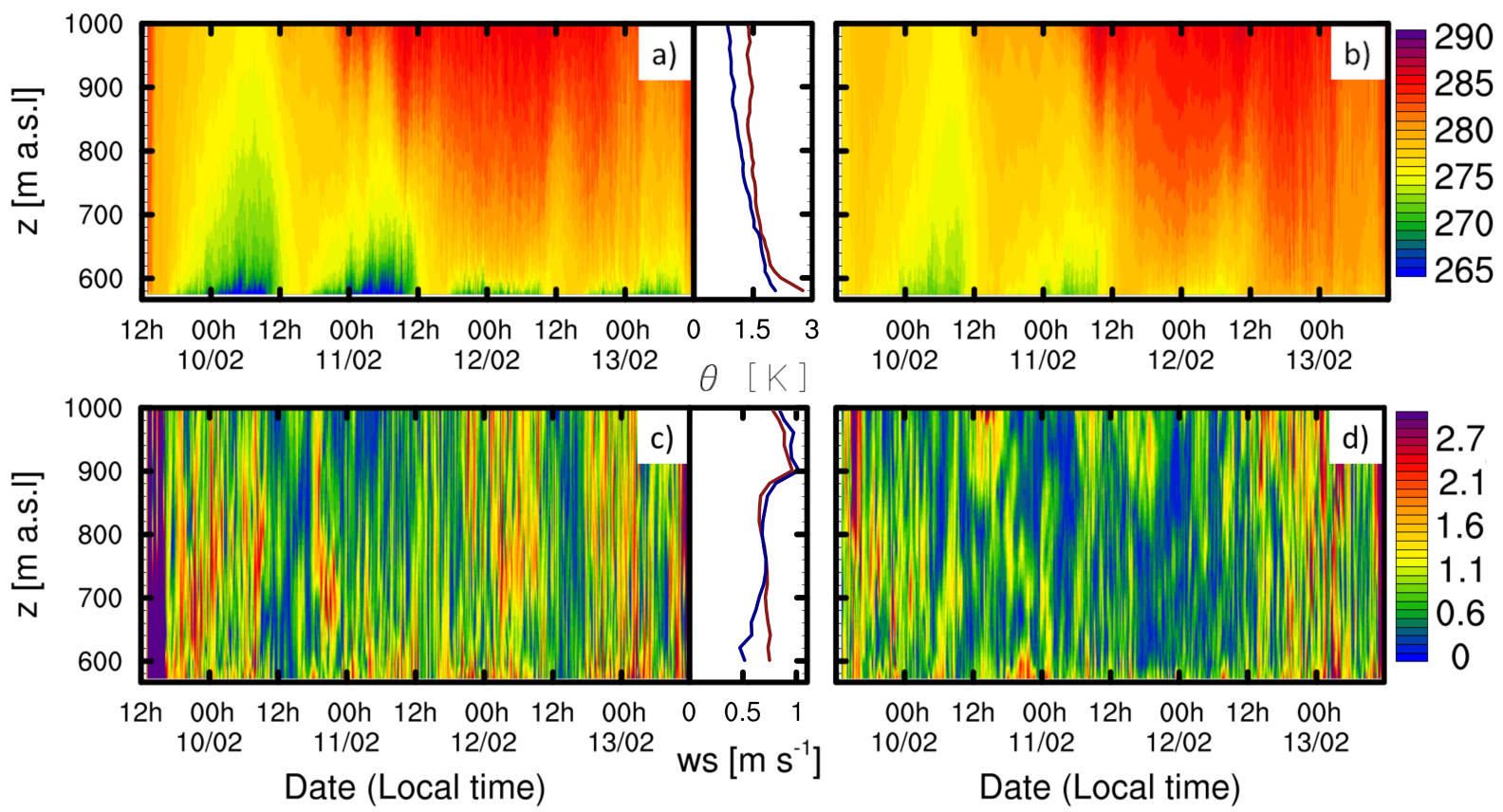

Figure 5: Temporal evolution of the vertical profile of the potential temperature (upper row) and wind speed (bottom row) computed by the present numerical simulation (left column) and by the simulation of Arduini et al. (2020) (right column) over a height of $440 \mathrm{~m}$ a.g.l. The computations were done at the location of the main measurement site of the Passy- 15 field campaign. Vertical profiles of the mean-absolute-error (MAE) between the numerical result and the field data are displayed, with red lines for the present simulation and blue lines for the simulation by Arduini et al. (2020).

though during the night a small overestimation of the con-534 centration is visible (see Fig. 6c). In Marnaz, the AQS wass35 unfortunately not functioning during the first half of the $\mathrm{IOP}_{536}$ However, the model shows a good agreement with the datas 37 available for the second part of the IOP (see Fig. 6d). $\quad{ }_{538}$

In light of these results, the performance of the model in ${ }_{39}$ the downstream section of the valley (Sallanches and Mar-540 naz) appears better than in the upstream section (Passy and541 Chamonix). Since the same emission inventory and emis-542 sion profile were used for the entire domain, we may con-543 clude that the atmospheric boundary layer is better repre-544 sented in the downstream section of the valley. $\quad 545$

In order to analyse the origin of the discrepancies be-546 tween the numerically predicted and the recorded concen-547 trations, the wind speed predicted by the numerical model ${ }_{48}$ and the emission profile used in that model are plotted with 549 the predicted $\mathrm{PM}_{10}$ concentration in Fig. 7, in Passy (Fig. 7a) and Sallanches (Fig. 7b). We first analyse the results obtained in Sallanches, which were shown to agree better with $^{550}$ the AQS data. The concentration follows the emission cycle, ${ }^{551}$ with peaks reached at about the same time. This behavior 52 is consistent with concentration building up from emission ${ }_{53}$ when the wind speed is weak. The wind speed displays ass4 daily cycle as expected, with a very weak speed indeed, at555 most $2.5 \mathrm{~m} \mathrm{~s}^{-1}$, which nearly vanishes around midday when ${ }_{556}$ it reverses between up- and down-valley directions (see $\mathrm{Ar}_{557}$ duini et al., 2020).

In Passy, the time series of $\mathrm{PM}_{10}$ concentration follows that of the emission profile in the morning (except on 12
February). By contrast, as already stressed above, the evening peak occurs too early, by about 4 hours with respect to the concentration at the AQS. The model predicts a nearly vanishing wind speed in the afternoon, during at least 6 hours, the wind increasing from about 1900 LT while remaining weak, less than $2 \mathrm{~m} \mathrm{~s}^{-1}$. The duration of the quasi-vanishing wind regime in the afternoon is surprisingly long. If not realistic, it would account for the too early peak of $\mathrm{PM}_{10}$, emissions accumulating without dispersion during the whole afternoon and early night.

Overall this detailed comparison shows a good agreement between the predictions of the numerical simulations and the measurements. The main difficulty is the numerical prediction of the wind speed in Passy during the day. This is challenging as this wind speed is very weak all day long at this location, less than $2 \mathrm{~m} \mathrm{~s}^{-1}$.

\section{Spatial distribution of the $\mathbf{P M} 10$ Concentration}

The present section analyses the spatial distribution of $\mathrm{PM}_{10}$ concentration in the Passy valley, as simulated by the model. The vertical distribution at the locations of the AQS is first considered, before analysing the horizontal distribution of the $\mathrm{PM}_{10}$ concentration in the Passy valley. The spatial distribution of the $\mathrm{PM}_{10}$ emissions is first computed and discussed.

The Passy valley was divided into seven subsections, represented as color areas in Fig. 1b. The relative importance 

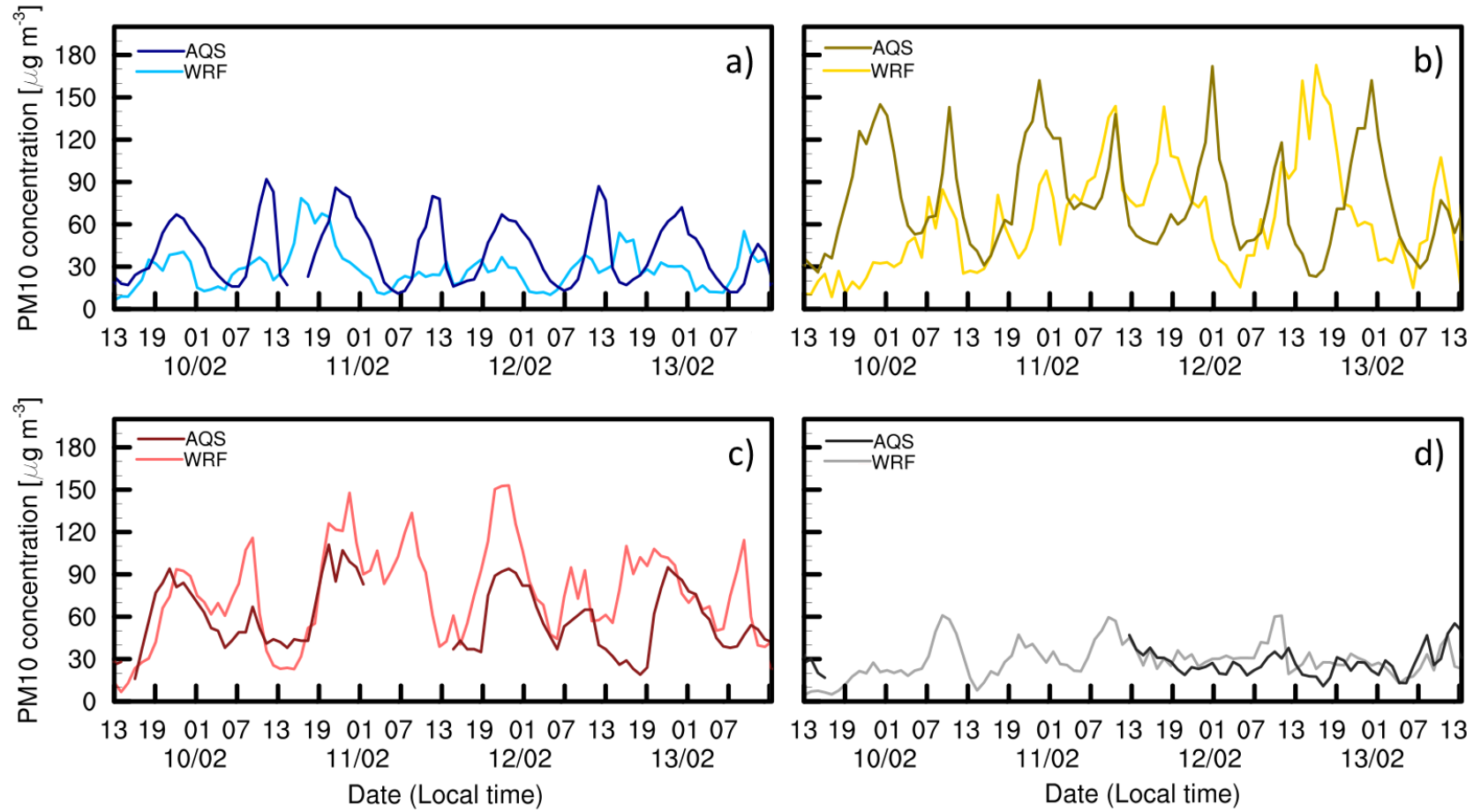

Figure 6: Hourly-averaged time series of the concentration of $\mathrm{PM}_{10}$ in $\mu \mathrm{gr} \mathrm{m}^{-3}$ in Chamonix (a), Passy (b), Sallanches (c) and Marnaz (d) using data collected at the AQS (dark lines), and results from WRF at those locations (light lines). The results of the model have also been averaged horizontally over a square of side $1 / 3 \mathrm{~km}$ centred about each AQS location and vertically over $10 \mathrm{~m}$ from ground level.

of emissions in the valley was estimated by computing, forso each area, the emission averaged over that area divided by5s1 the total emission averaged over the total color area, namely5s2

$$
R_{Q Q_{i}}=\frac{\left\langle Q>_{A_{i}}\right.}{\left\langle Q>_{\sum_{i=1}^{7} A_{i}}\right.},
$$

where $A_{i}$ is one of the seven areas $(1 \leq i \leq 7)$ and $\sum_{i=1}^{7} A_{i_{588}}^{587}$ is the total color area displayed in Fig. 1a (the emission rate $Q$ is integrated over one hour). Time series of $R_{Q Q_{i}}$ for each $_{590}^{589}$ subsection are displayed in Fig. 8 for the simulated time pe- ${ }^{590}$ riod. As expected, all curves follow the emission profile im- ${ }^{591}$ posed in the numerical model (displayed in Fig. 2). However ${ }^{52}$ emissions are larger by a factor about two in the subsection ${ }^{593}$ involving the town of Passy due to sources associated with ${ }^{594}$ domestic heating and with industrial activities in this valley ${ }_{500}^{59}$ subsection. The second largest emission area is the subsection involving the town of Sallanches. Emissions are similar in all other subsections, except in the one located between ${ }^{598}$ Passy and Sallanches where emission is smallest because the ${ }^{599}$ landcover mainly consists in fields.

Fig. 9 displays the vertical profiles versus time of the $\mathrm{PM}_{10}$ concentrations predicted by the model at the AQS $10^{602}$ cations. These profiles extend over a height of $400 \mathrm{~m}$ a.g.l. ${ }^{603}$ The figure displays several striking points. First the $\mathrm{AQS}^{604}$ locations can be divided into two distinct groups, those $10^{605}$ cated inside the valley core, in Passy and Sallanches, and ${ }_{607}^{606}$ those located outside that core, in Marnaz and Chamonix.
This distinction is already present in the emission profiles (see Fig. 8) but not so clearly. Since the concentration field results from the combined effect of emission and transport of these emissions by the wind, the wind field should be considered to fully account for the behavior observed in Fig. 9. The latter point is investigated in section 5 .

The $\mathrm{PM}_{10}$ concentration profiles in Passy and Sallanches display a similar distribution (see Fig. 9b and 9c): the highest concentration levels, up to $130 \mu \mathrm{gr} \mathrm{m}^{-3}$ are found at these locations and the values larger than $100 \mu \mathrm{gr} \mathrm{m}^{-3}$ remain concentrated in a layer of about $50 \mathrm{~m}$ a.g.l.. These results are consistent with concentration measurements reported during stable wintertime conditions in the Inn valley by Gohm et al. (2009). The whole concentration field does not extend beyond $400 \mathrm{~m}$, except for a convective plume around noon on the 10 February that reaches $500 \mathrm{~m}$ or so. A mixed layer is actually observed in Sallanches and Passy in the early afternoon during that day, temporally decreasing the concentration at the ground. The concentration also decreases in the early morning of 12 February, due to the acceleration in the wind speed (up to $2.5 \mathrm{~m} \mathrm{~s}^{-1}$ ) observed in Sallanches, and to a lesser extent in Passy, at that time (see Fig. 7). This down-valley wind transports pollution further down, thereby cleaning the valley core but increasing the $\mathrm{PM}_{10}$ concentration in Marnaz during the same time period (see Fig. 9d).

Numerical predictions at the AQS locations in Chamonix and Marnaz display similar concentration fields, both in amplitude and height, but the concentration values are much 


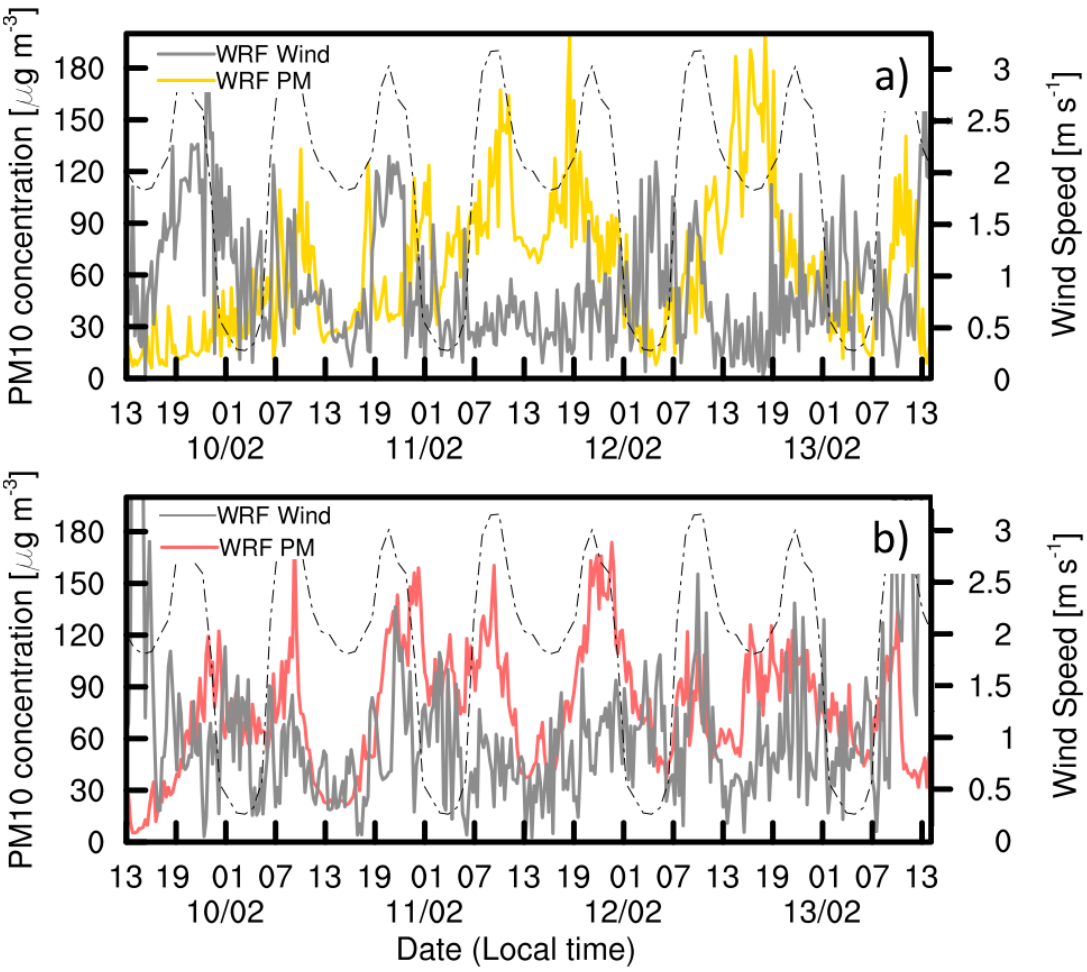

Figure 7: Time series of the concentration of $\mathrm{PM}_{10}$ in $\mu \mathrm{gr} \mathrm{m}^{-3}$ (color lines) and the horizontal wind speed (grey lines) using results of the simulations. The results of the model have been averaged in time over 15 minutes, over a horizontal square of side $1 / 3 \mathrm{~km}$ centered about each AQS and vertically over $10 \mathrm{~m}$ from ground level. The emission profile has been added (dashed line) as a reference (with no unit). The calculations have been done for the positions of the AQS at Passy (a) and Sallanches (b).

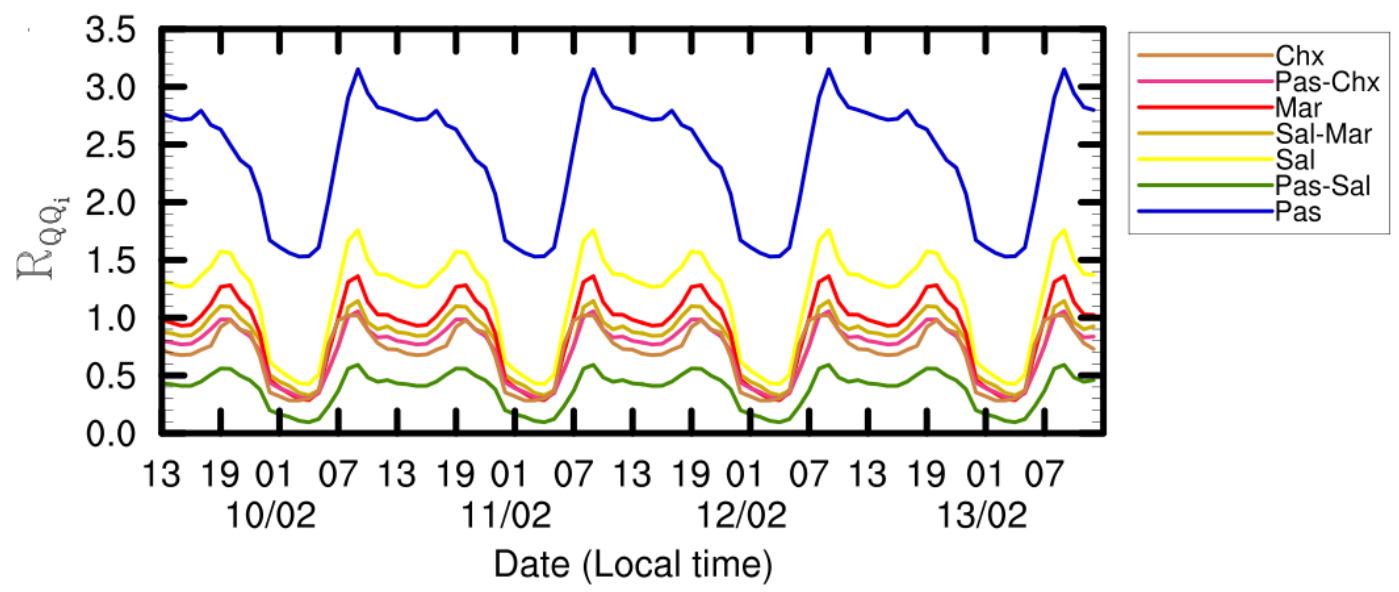

Figure 8: Emissions released in each of the subsections defined in Fig. 1a, averaged over that subsection, normalized by the total emission over the Passy valley domain, averaged over that domain (see Eq. (1) for a mathematical definition of $R_{Q Q_{i}}$ ).

lower than in the valley core (see Fig. 9a and 9d). Thissis is consistent with the emission levels reported in Fig. $8_{617}$ However those levels are relatively close in Marnaz and Sal-r1s lanches, suggesting a marked impact of the wind field. Quiteo19 remarkably, the concentration field remains trapped in a shal-620 low layer of height $50 \mathrm{~m}$ above the ground, implying a strong $g_{21}$ stratification of the air layer. Exceptions are the afternoon of f22 $_{22}$ the 10 February in Chamonix, probably because of convec-623 tive activity, and in the early morning of the 12 February in Marnaz as discussed above.

Figure 10 presents $\mathrm{PM}_{10}$ horizontal concentration averaged over six hours (so as to smooth out discrepancies due to shifts in time in the model results) for a 24-h period during the core of the PCAP episode. Urban areas, indicated as black contours in Fig. 10, appear as hotspots of pollution. More precisely the central part of the valley, where the cities 

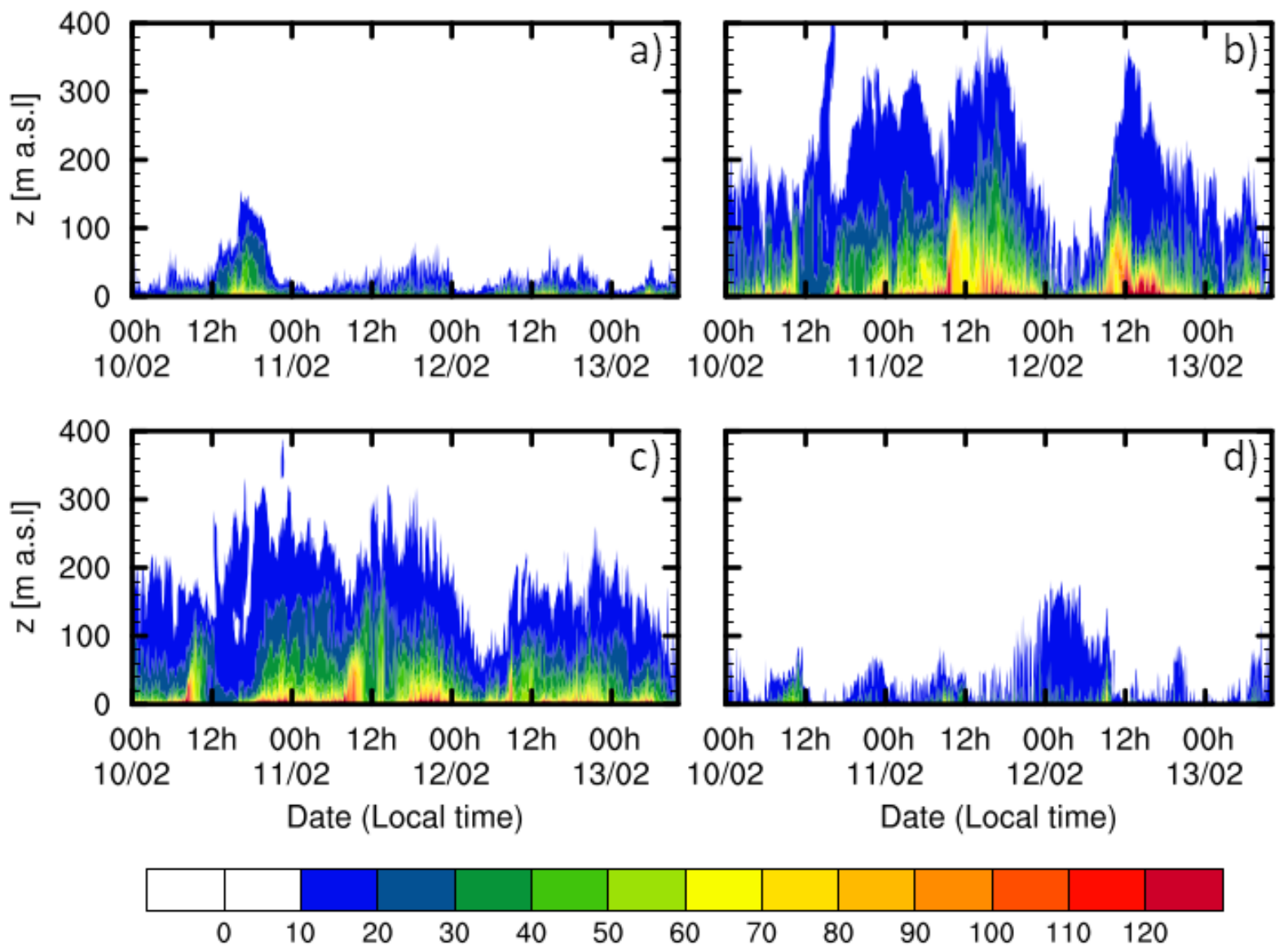

Figure 9: Temporal evolution of the vertical profiles of the $\mathrm{PM}_{10}$ concentration in $\mu \mathrm{gr} \mathrm{m}^{-3}$ at the locations representing the AQS in the domain (Chamonix (a), Passy (b), Sallanches (c) and Marnaz (d)). The results of the model have been averaged over a horizontal square of side $1 / 3 \mathrm{~km}$ centered about each AQS.

of Passy and Sallanches are located, display important ac-646 cumulations of $\mathrm{PM}_{10}$ : average values are above $50 \mu \mathrm{gr} \mathrm{m}^{-3}{ }_{647}$ and peak concentrations up to about $150 \mu \mathrm{gr} \mathrm{m}^{-3}$ are foundb48 in larger areas in the morning and evening rush hours. Pollu-649 tion is also found in the town of Chamonix, though at a lessoso striking level, with localized areas where the concentration is higher than $55 \mu \mathrm{gr} \mathrm{m}^{-3}$ in the morning and early afternoon. ${ }^{651}$ By contrast, the tributary valleys of Megève and St-Gervais ${ }^{652}$ do not experience high levels of $\mathrm{PM}_{10}$ : the concentration is ${ }^{653}$ always below $30 \mu \mathrm{gr} \mathrm{m}^{-3}$. Fig. 10 shows that four pollution ${ }^{54}$ hotspots can be identified: in the town of Passy, downstream ${ }^{65}$ of the monitoring station in Sallanches, upstream of the val-656 ley exit (near Magland) and on the west side of Marnaz. The ${ }^{657}$ analysis of the wind field in the next section helps to clarify ${ }^{658}$ this behavior.

\section{Stagnation and ventilation zones in the Arve river valley}

The objective of this section is to estimate the transport ${ }^{663}$ potential of pollution by the flow field. For this purpose, the ${ }_{664}$ method proposed by Allwine and Whiteman (1994) is used to compute stagnation, recirculation and ventilation zones. This method was originally designed when measurements at665 a single station are available (a synthetic account is provided by Cook et al., 2011). In the present work, the method is applied to each grid point of the innermost domain allowing for a complete picture of the transport properties of the flow over time in the Passy valley.

\subsection{Principle of the method}

The method proposed by Allwine and Whiteman (1994) relies on times series of the horizontal velocity components at a fixed height in the atmosphere. Let $T$ be the length of the time series, sampled into $n$ intervals of length $\tau$ over which the data are averaged (for instance $T=24 \mathrm{~h}, \tau=10 \mathrm{~min}$ ). The speed and direction of the horizontal velocity field are next computed over each $\mathrm{i}^{\text {th }}$ interval, $1 \leq i \leq n$. Allwine and Whiteman (1994) introduced two parameters:

- The wind run $S_{i}$, defined as the virtual distance that an air parcel would travel during the $\mathrm{i}^{\text {th }}$ time interval, assuming that it does not experience any change in speed or direction. At the end of the time period $T$, a parcel has travelled the virtual distance $S=\sum_{i=1}^{n} S_{i}$.

- the recirculation index $R$ defined by $R=1-\frac{L}{S}$, where 

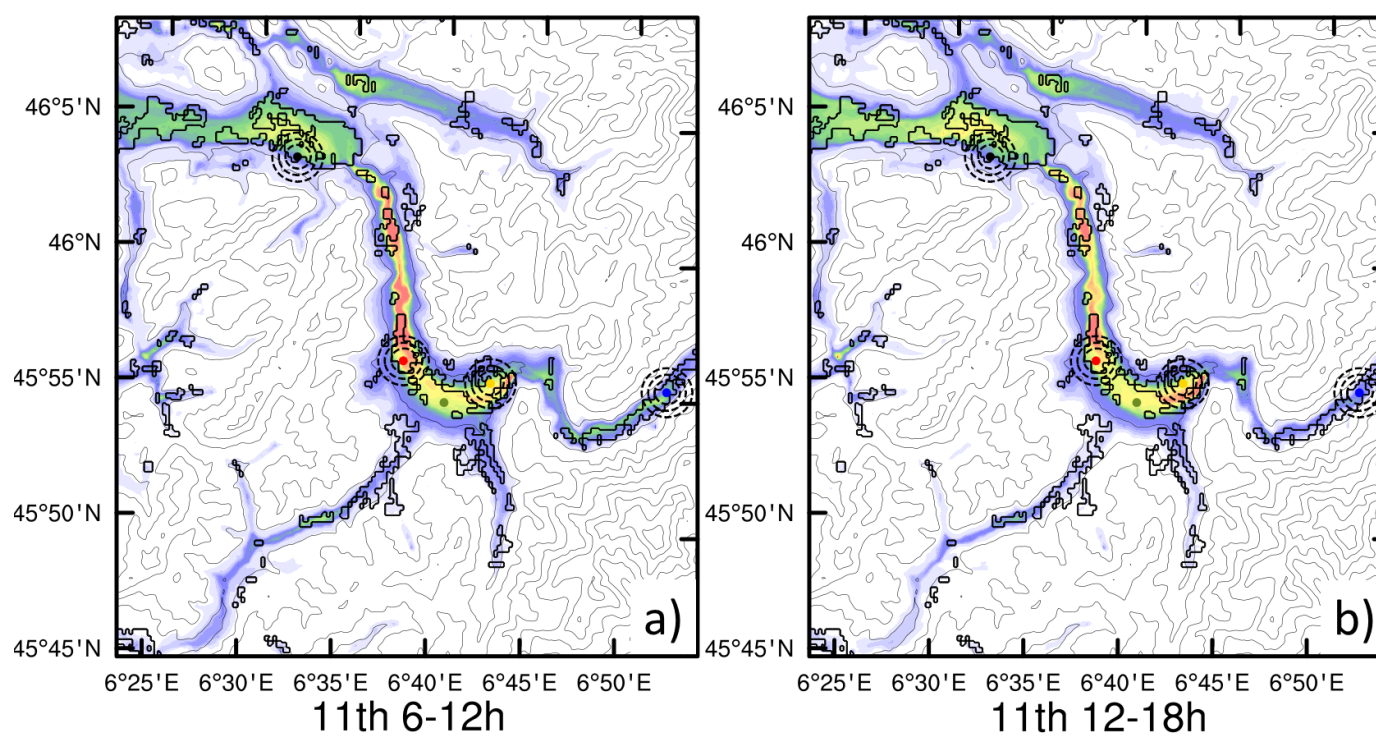

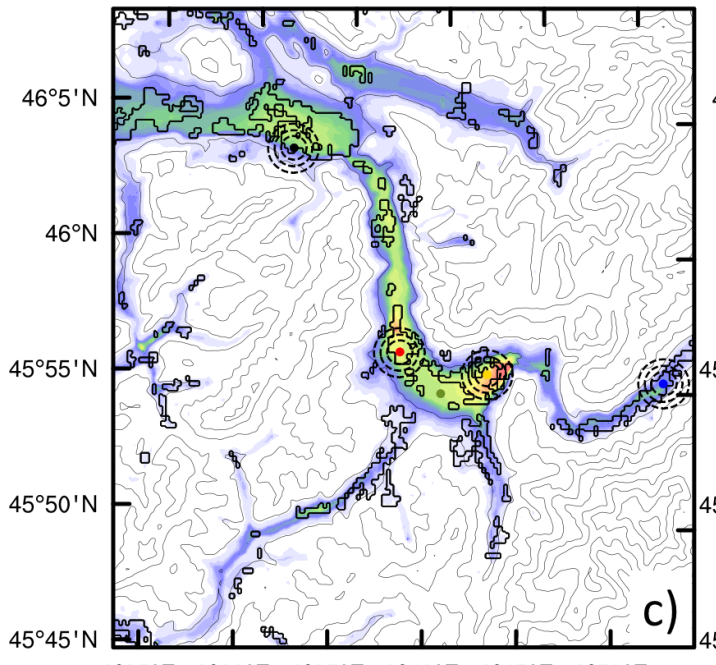

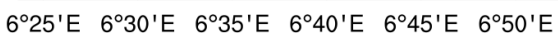

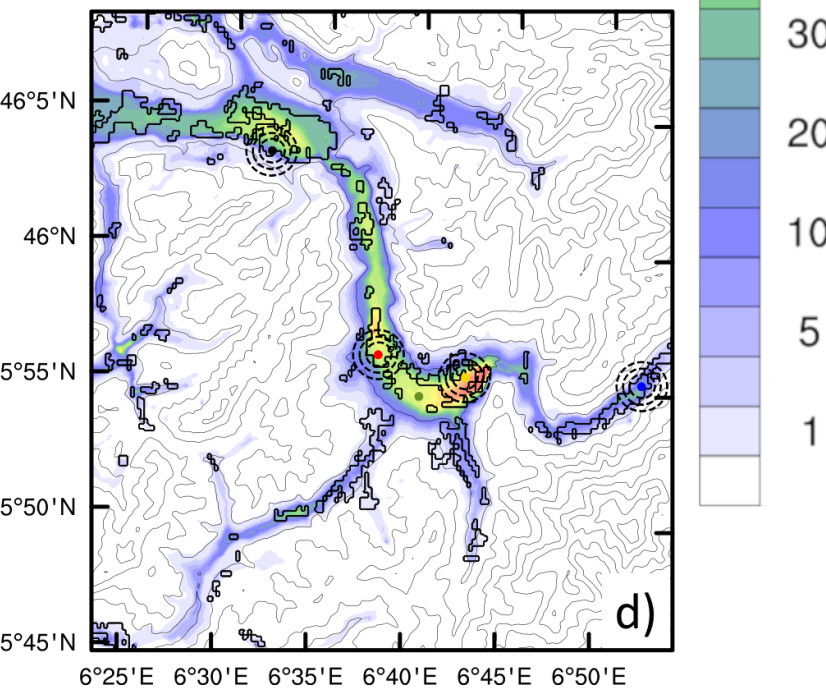

Figure 10: Contour plots of six-hour average of $\mathrm{PM}_{10}$ concentration $\left[\mu \mathrm{gr} \mathrm{m}^{-3}\right]$ averaged along the vertical in the first 10 $\mathrm{m}$ above the ground overlayed with contour lines of the terrain height. Black contours indicate urban areas in the domain. The locations of the air quality stations in the zone are marked with coloured dots; Chamonix (blue), Passy (yellow), Sallanches (red) and Marnaz (black). The exact locations of the stations are documented in Table 3. The location of the main measurement site in Passy-15 is denoted with the green dot.

$L$ is the effective distance travelled by the fluid particlesso over time $T$ (see Figure 11).

When $S$ is much larger than $L, R$ tends to 1 . This means $s_{82}$ that an air parcel following the flow has travelled some dis- ${ }_{683}$ tance, but its final position remains close to its initial position: the parcel has experienced recirculation.

When $S$ is of order $L, R$ tends to 0 . If $S$ is large enough, ${ }^{685}$ this means that the air parcel has travelled far away from its initial position: it has experienced ventilation.

Finally, if $S$ is small enough (whatever $R$ ), the parcel is ${ }^{687}$ trapped in a stagnation zone.

For practical application, the notions of recirculation, ${ }^{688}$ nation and ventilation therefore require the definition of threshold values, also referred to as critical values. These critical values are denoted $S_{c}, S_{c v}, R_{c}$ and $R_{c v}$ and are defined as follows:

- if $S \leq S_{c}$ in a given zone, this zone is defined as a stagnation zone;

- if $R \geq R_{c}$ in a given zone, this zone is defined as a recirculation zone;

- if $R \leq R_{c v}$ and $S \geq S_{c v}$ in a given zone, this zone is defined as a ventilation zone.

\subsection{Choice of the values of the critical parameters}

The computation of these different zones requires to assign values to the critical parameters and to choose the length 


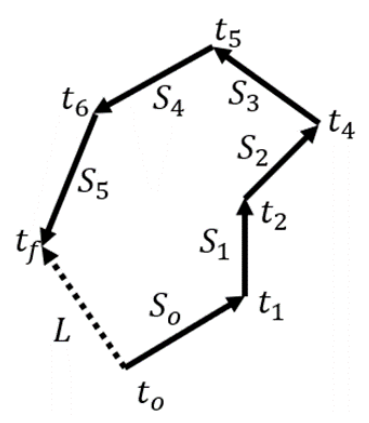

Figure 11: Sketch of the definitions of the wind run $\left(S_{i}\right)$ and of the transport distance $(L)$. Note that the end of each arrow in the figure corresponds to a time, not a point in space. Adapted from Allwine and Whiteman (1994).

of the time series $T$. This length is usually set to $24 \mathrm{~h}$ in complex terrain. There is no method to choose the critical values (see Cook et al., 2011, for a discussion). In Allwine and Whiteman (1994) for instance, these values are defined from the average values of $R$ and $S$ over a three-month winter period, computed separately for two sites in the Colorado Plateau basin, USA.

In the present case, the critical values are determined from the data recorded at the main measurement site of the Passy-15 field campaign. These data are the horizontal velocity components of the wind recorded at the first level of the LiDAR (40 m a.g.1.), and over three months of the 20142015 winter. Once the critical values have been chosen, we apply the method of Allwine and Whiteman (1994) to all grid points of the innermost domain (see section 5.3).

The wind run $S$ and the index $R$ have first been computed ${ }_{733}^{732}$ for $\tau=10 \mathrm{~min}$ and for different values of $T$, equal to $6 \mathrm{~h}, 12 \mathrm{~h}$ and $24 \mathrm{~h}$ (see Fig. 12). If we define the critical value of $S_{734}$ from its average value over the three-month winter period ${ }_{735}$ then $T=6 \mathrm{~h}$ is preferable. Indeed, this average value is ${ }_{736}$ equal to $20 \mathrm{~km}$ for $T=6 \mathrm{~h}, 34 \mathrm{~km}$ for $T=12 \mathrm{~h}$ and $64 \mathrm{~km}$ for $T=24 \mathrm{~h}$. These values correspond to a wind of $0.9 \mathrm{~m} \mathrm{~s}^{-1}{ }_{738}^{737}$ which is a light wind speed in line with the recorded values ${ }_{739}$ If we were choosing $T=24 \mathrm{~h}$ and set $S_{c}$ to $64 \mathrm{~km}$ then the ${ }_{740}$ whole valley would be a stagnation zone because the length ${ }_{741}^{740}$ of the valley is $25 \mathrm{~km}$ from Passy to Marnaz (the conclusion ${ }_{742}$ is the same for $T=12 \mathrm{~h}$ ). We therefore choose $T=6 \mathrm{~km}_{743}$ and set $S_{c}$ to $20 \mathrm{~km}$. The critical value for ventilation $\mathrm{S}_{c v_{74}}^{743}$ is set to $32 \mathrm{~km}$, corresponding to an average wind speed of ${ }_{745}$ about $1.5 \mathrm{~m} \mathrm{~s}^{-1}$, which can flush the whole valley during $T=6 \mathrm{~h}$. Fig. 12a shows that $S$ has values below $\mathrm{S}_{c}$ about ${ }_{747}$ $60 \%$ of the time and above $\mathrm{S}_{c v}$ about $15 \%$ of the time.

The time series of $R$ over the three-month period is dis- ${ }^{748}$ played in Fig. 12b. The average value of $R$ is equal to $0.43_{750}$ for $T=6 \mathrm{~h}(0.5$ for $T=12 \mathrm{~h}$ and 0.56 for $T=24 \mathrm{~h})$. All $^{-751}$ wine and Whiteman (1994) set $\mathrm{R}_{c}=0.6$, corresponding to the ${ }_{752}$ resultant distance $L$ being equal to $40 \%$ of the total wind run $_{753}$ over the time $T$. In the same way, they set $R_{c v}=0.2$, $^{-{ }^{-}}{ }_{754}$ responding to the resultant distance being equal to $80 \%$ of $_{755}^{754}$ the wind run over the same time. The same values are used ${ }_{756}$ here for $R_{c}$ and $R_{c v}$. With these choices, the average value ${ }_{757}$
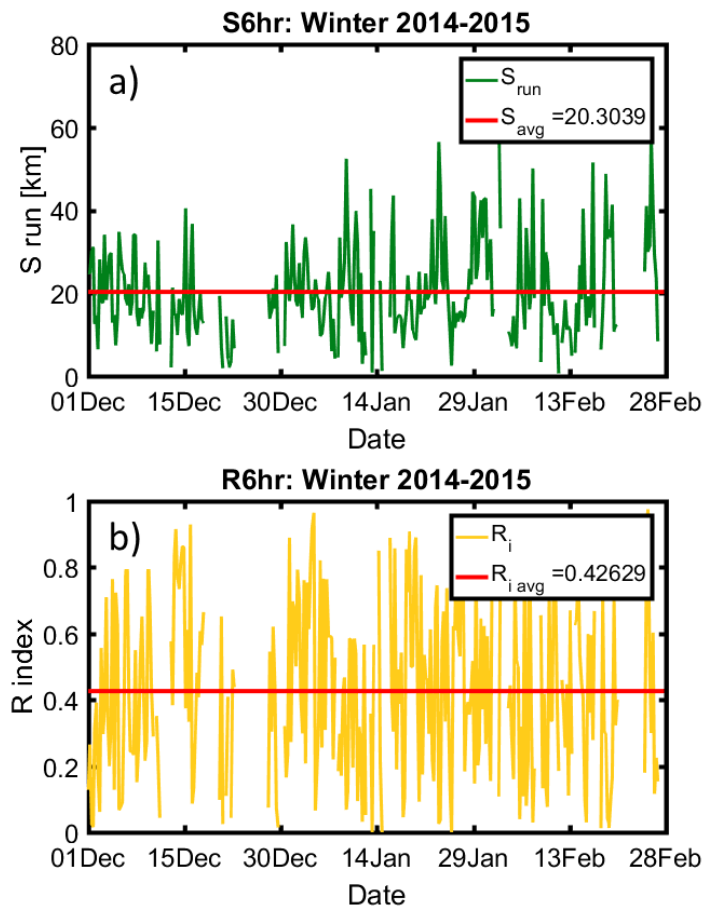

Figure 12: Timeseries of the wind run S (a) and the recirculation index R (b) for the winter of 2014-2015 (1st December 2015 to the 28th February 2015). The horizontal velocity components of the wind recorded at the first level of the $\mathrm{Li}$ DAR (40 m a.g.l.) have been used to compute $S$ and $R$, for $T=6 \mathrm{~h}$ and $\tau=10 \mathrm{~min}$.

of about 0.5 found for $R$ already implies a general trend for recirculation and stagnation in the Passy valley.

\subsection{Stagnation, recirculation and ventilation zones in the Passy valley}

Largeron (2010) improved the classification by including two additional categories (critical stagnation and low ventilation) based on Allwine and Whiteman (1994) method. This classification is indicated in Table 4, with the present values for the critical parameters. These categories are designed to cover all possible conditions for pollutant transport from the worst condition (critical stagnation), for which pollutants remain trapped and accumulate, to the best condition (ventilation) for which pollutants are transported away from the measurement site. In the present work we merge Low ventilation and Ventilation in a single category.

When the innermost domain is mapped using these categories, regions ranging from critically-stagnant zones to ventilated zones are identified (see Fig. 13). The tributary valleys of Megève and Saint-Gervais, on the south part of the domain, and the section of the valley between Passy and Chamonix are ventilated zones in all frames of Fig. 13, being associated with valley flows. Yet, the bottom part of these sections, namely the core of the Passy valley, is not ventilated: the section around Sallanches lies in a stagnation zone in all frames, that around Passy lies most of the time in a critically stagnant zone and the section between 
Drivers of severe air pollution events in a deep valley during wintertime

\begin{tabular}{|c|c|c|}
\hline Categorie & Criterium & Thresholds \\
\hline Critical stagnation (SC) & $S \leq S_{c}$ and $R \geq R_{c}$ & $S_{c}=20 \mathrm{~km}, R c=0.6$ \\
\hline Stagnation (S) & $S \leq S_{c}$ and $R \leq R_{c}$ & $S_{c}=20 \mathrm{~km}, R c=0.6$ \\
\hline Recirculation (R) & $R \geq R_{c}$ & $S_{c}=20 \mathrm{~km}, R c=0.6$ \\
\hline & $S_{c} \leq S \leq S_{c v}$ and $R \leq R_{c}$ & $S_{c}=20 \mathrm{~km}, R c=0.6$ \\
or & $S_{c v}=32 \mathrm{~km}, R_{c v}=0.2$ \\
\hline Low ventilation (V) & $S \geq S_{c v}$ and $R_{c v} \leq R \leq R_{c}$ & $S_{c}=20 \mathrm{~km}, R c=0.6$ \\
\hline Ventilation (LV) & $S \geq S_{c v}$ and $R \leq R_{c v}$ & $S_{c v}=32 \mathrm{~km}, R_{c v}=0.2$ \\
\hline
\end{tabular}

Table 4: Definition of the five categories to characterize the transport properties of the flow based on Largeron (2010). The critical values for the wind run have been modified to better describe the wind structure in the Arve River Valley at the main measurement site (represented by a green dot in Fig. 1b). The critical values have been computed for $T=6 \mathrm{~h}$. In Fig. 13, the last two categories have been merged.

\section{Local and Non-local Contributions}

The relative contributions of the $\mathrm{PM}_{10}$ emissions of each $_{820}$ of the seven subsections of the valley to the total $\mathrm{PM}_{10}$ con- $_{821}$ centration at the location of the air quality monitoring sites ${ }_{822}$ (Chamonix, Passy, Sallanches and Marnaz) are presented in $_{\mathbf{8 2 3}}$ Fig. 14. More precisely, Fig. 14 displays the ratios

$$
\frac{<C_{i}>_{A Q S_{j}}}{<\sum_{i=1}^{7} C_{i}+\text { Rest }>_{A Q S_{j}}},
$$
for $i$ comprised between 1 and 7 and $j$, between 1 and $4_{829}$ Each index $i$ is associated with a color, and the same color convention as in Fig. 8 is used. "Rest" represents the tracers being emitted in the innermost domain but outside the seven subsections.

In the upstream section of the valley at Chamonix (see Fig. 14a) $\mathrm{PM}_{10}$ pollution is originating almost entirely from local sources throughout the episode. This result can be accounted by the fact that no source are considered upstream of the Chamonix valley subsection and that the valley flow is down-valley in this subsection. This finding is consistent with a previous study by Chazette et al. (2005), which highlighted the importance of local emission sources on the concentration of wintertime pollution at this site.

The total concentration of $\mathrm{PM}_{10}$ recorded in Passy is dominated by the contribution of local sources emitted at Passy, with an average of $74 \%$ throughout the episode (see Fig. 14b). This confirms the decoupled character of this section of the valley during the persistent stage of the episode (10 - 13 February) pointed out in Sect. 5. It is worth noting that the contributions from the downstream sections are almost zero, suggesting that no up-valley flow is present there during the episode. Relatively small contributions originate from Chamonix and from the tributary of St-Gervais (see the brown line and the black line in Fig. 14b, respectively), especially at night, suggesting that part of the flow from these tributaries is able to penetrate the CAP. This suggests that, as deduced by Sabatier et al. (2018), the tributaries can make a contribution (about 15\% when averaged throughout the episode) to the pollution recorded at Passy.

The situation is more complex in Sallanches (see Fig. $14 \mathrm{c}$ ), where strong interactions take place with the surroundings subsections. Although the average emissions released from this section are the second largest in the domain (see Fig. 8a), the contribution from local sources is not as high (43\%) as reported for the upstream section (74\%). The contribution of the subsection linking Sallanches and Marnaz is relatively small (less than $10 \%$, see the gold line in Fig. 14c) because the valley flow is primarily down-valley. The contribution of $\mathrm{PM}_{10}$ emissions sources from the subsection in Passy is very important, with an average of $25 \%$ throughout the episode. Note that a daily cycle can be identified in the timeseries, with a large contribution from Passy during the 
10th $18-24 \mathrm{~h}$

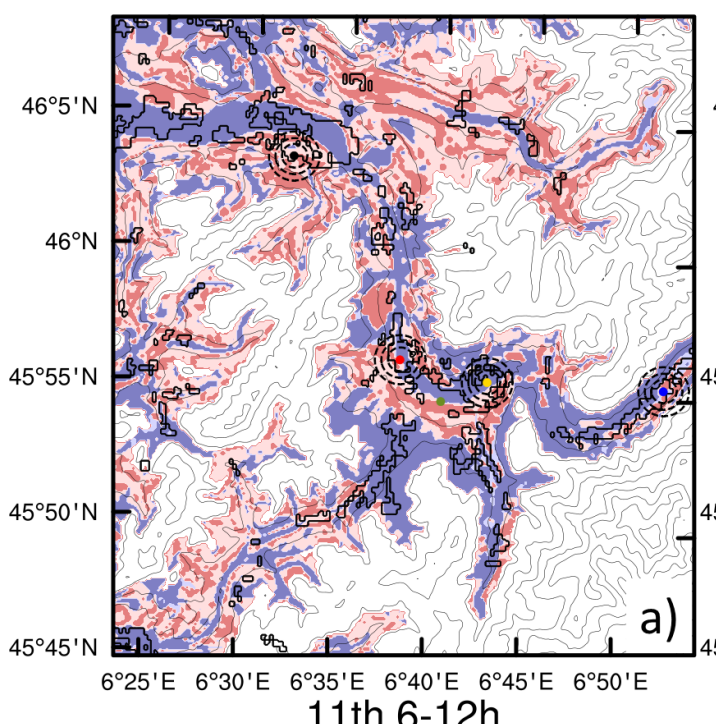

11 th $6-12 h$

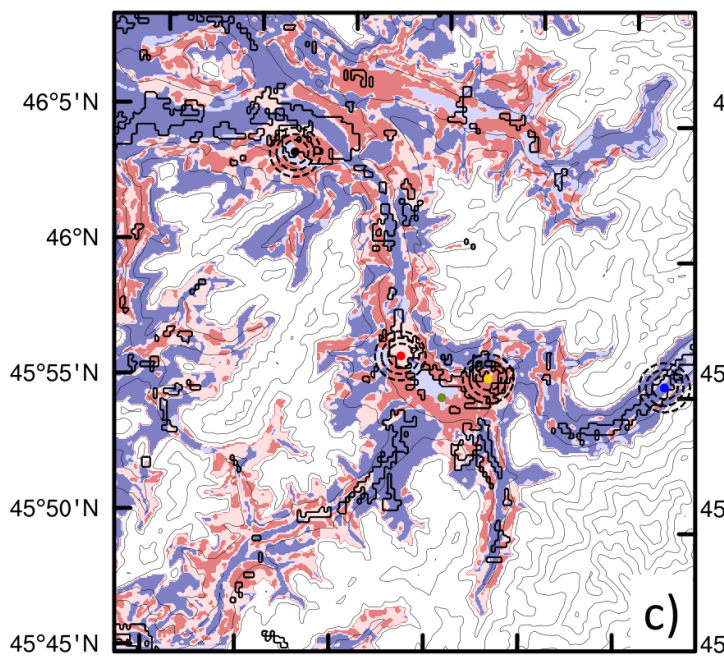

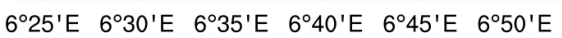

11 th $0-6 \mathrm{~h}$

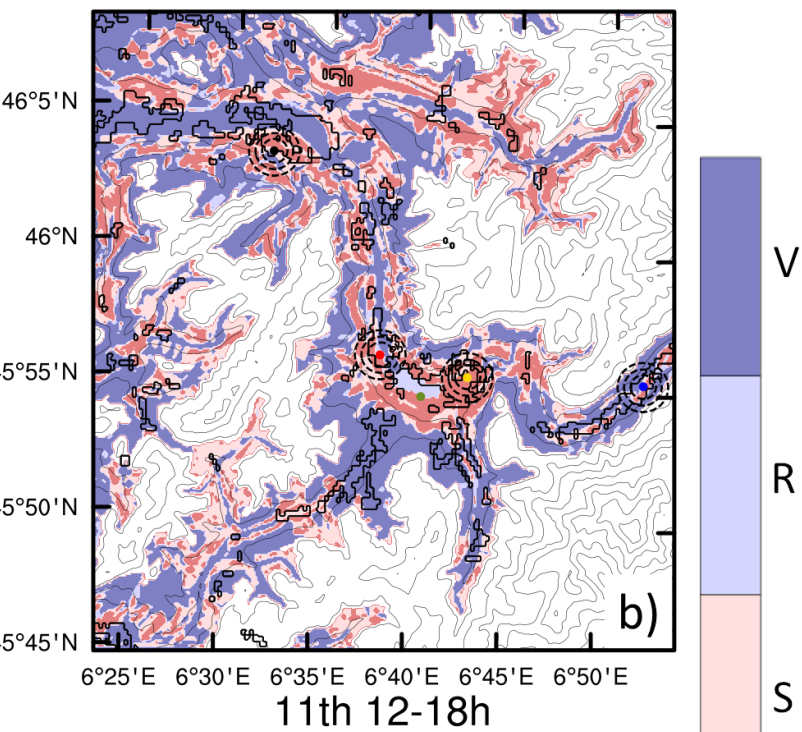

S

CS

Figure 13: Maps tracking the zones prone to critical stagnation (CS), stagnation (S), recirculation (R) and ventilation (V) using a six-hour average in time and averaged along the vertical in the first $10 \mathrm{~m}$ above the ground. The results have been overlayed with contour lines of the terrain height. The data is masked to show the information only for terrain height lower than $1500 \mathrm{~m}$ a.s.l. Black contours indicate urban areas in the domain. The locations of the air quality stations in the zone are marked with coloured dots; Chamonix (blue), Passy (yellow), Sallanches (red) and Marnaz (black). The exact locations of the stations are documented in Table 3. In addition, the location of the main measurement site in Passy-15 is denoted with the green dot.

night, while the export of pollution ceases during the day. Fi-842 nally, the contribution from the tributary leading to Megève (see the black line in Fig. 14c) reaches values as high as 27\% for short periods of time.

In Marnaz (see Fig. 14d) the contribution of local source 44 to the local PM10 pollution is about $70 \%$ on average durings45 the episode. A daily cycle is also visible in the timeseries.846 During the night, non-local pollution increases, especiallys47 from sources outside the seven subsections (see the blacksas line in Fig. 14d). Note that the peaks in the contributionsas of these sources match very well with the peaks for the up-850 stream sources, suggesting that these sources are located inss1 the upstream part of the valley.

\section{Discussion and conclusions}

A real-case simulation of the particulate-matter transport processes in a section of the Arve river valley (northern French Alps) was performed using the Weather Research and Forecasting (WRF) model. The influence of the valley-wind system on the ventilation of pollutants and the effect of very local pollution sources on the resultant pollutant concentration in such a deep alpine valley when subject to wintertime anticyclonic conditions was quantified. The results about 
Drivers of severe air pollution events in a deep valley during wintertime
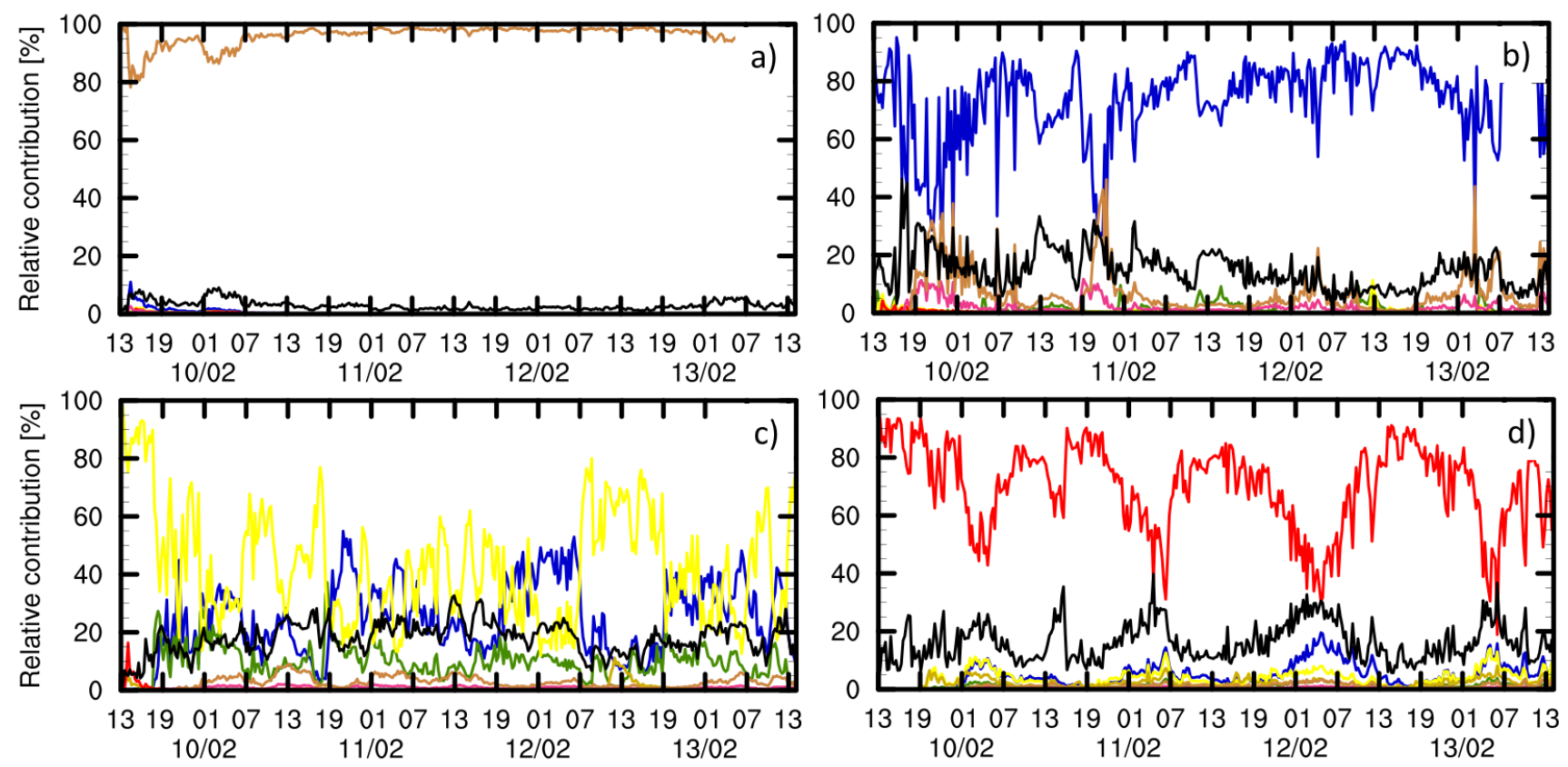

Local time Local time

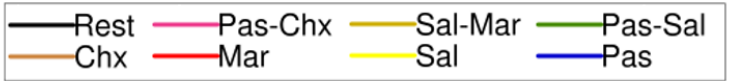

Figure 14: Time series of the relative contributions of $\mathrm{PM}_{10}$ emissions of each of the seven subsections of the valley previously defined (see fig. 1b) to the total $\mathrm{PM}_{10}$ concentration at the location of the AQS of Chamonix (a), Passy (b), Sallanches (c) and Marnaz (d) using data produced in the innermost domain d05. This relative contribution is defined by Eq. 2. The results of the model have been averaged in time every 15 minutes and in space over a horizontal square of side $1 / 3 \mathrm{~km}$ centered about the location of AQS; an average is also performed over the first $10 \mathrm{~m}$ above ground level.

the flow dynamics presented here are based on a previouss77 work developed by Arduini et al. (2020). The simulations878 reproduce the pollution episode associated with the first in-879 tensive observation period (IOP1) of the Passy- 15 field cam-8so paign (Staquet et al., 2015, Paci et al., 2017) which was con-8s1 ducted in the surroundings of the town of Passy during thessz second week of February 2015. The ability of the model toss accurately simulate the concentration of $\mathrm{PM}_{10}$ in the valley8s4 from realistic emission sources has been tested against datar85 recorded by four air quality stations (AQS) in the area (Cha-8s6 monix, Passy, Sallanches and Marnaz, see Fig. 1). An anal-887 ysis was then developed to account for the distribution of $f_{88}$ pollution in the valley from the simulated atmospheric dy-889 namics and the emission sources. The main results of this study are summarized as follows:

- A sensitivity test was conducted by running the simu $\$ \mathbf{8 2}$ lation continuously for four days of the IOP (instead of ${ }^{893}$ being run over $24 \mathrm{~h}$ during 4 consecutive days) and bys94 improving the vertical resolution close to the ground, ${ }^{895}$ with the first mass point at $4.6 \mathrm{~m}$ above the ground ${ }^{96}$ level ( $\mathrm{m}$ a.g.l.) and the double of grid points in these first $200 \mathrm{~m}$ a.g.l. (17 grid points in the first $200 \mathrm{~m} \mathrm{~m}^{\mathrm{9}}$ a.g.l.). We found that these changes do not improveseg comparison with the field data. Indeed, the differencesoo in the mean-absolute errors for each simulation rela-901 tive to the field data is close to the accuracy of the instruments. We conclude that a better representation of the boundary conditions, terrain characteristics and surface forcing is rather required to improve the representation of the heat and moist fluxes from the soil to the atmosphere, and of the flow field close to the ground (see f.i. Chow et al., 2006, Rasheed et al., 2011, De Meij and Vinuesa, 2014, Rendón et al., 2014, Foster et al., 2017, Wagner et al., 2019). Taking the effect of the $\mathrm{PM}_{10}$ particles on radiative transfer could also improve the comparison as the air temperature and wind speed were both found to overestimate the values of the field data (see f.i. Nair et al., 2017).

- The model performance was evaluated by comparing the simulated concentration of $\mathrm{PM}_{10}$ in the domain with data recorded by the air quality stations (AQS) in the area. The correct magnitude of the concentration is well captured throughout the domain (see Fig. 6). However, the simulated concentration of $\mathrm{PM}_{10}$ at the Sallanches and Marnaz AQS locations show better agreement with the data collected by the AQS than the simulated concentration of $\mathrm{PM}_{10}$ at the Chamonix and Passy AQS locations. The main discrepancy occurs in Passy, where the simulated $\mathrm{PM}_{10}$ appears to peak too early in the evening compared to the AQS 
data (about four hours earlier). Because of the time atoss which the AQS reports those peaks (around midnight),959 it seems that this discrepancy is not a consequence of $f_{60}$ the release of emissions in the model but should beo61 attributed to the dynamic characteristics of the atmo-962 sphere at Passy. Indeed, the flow close to the ground ino63 Passy nearly vanishes around noon and remains very964 weak (less than $0.5 \mathrm{~m} \mathrm{~s}^{-1}$ ) up to about $1900 \mathrm{LT}$, an un-965 expected behavior which may account for the too early966 peak of $\mathrm{PM}_{10}$ concentration.

967

- From the measurements of the AQS available across ${ }^{968}$ the valley, an unusual horizontal distribution of pol- $^{969}$ lution was observed, with hotspots of $\mathrm{PM}_{10}$ concen- ${ }^{970}$ tration in localized sites throughout the central part of ${ }^{971}$ the Passy valley. These sites prone to high $\mathrm{PM}_{10}$ pol- $_{972}$ lution are normally associated with urban areas $\left(\mathrm{See}_{973}\right.$ Fig. 10). To understand the distribution of pollutants in the domain we divided the valley into seven sections ${ }_{975}$ (see Fig. 1b), which allowed us to track the evolution ${ }_{976}$ in time and space of pollutants released in each of the ${ }_{977}$ valley section. The section with the highest amount of released pollution is that of Passy, even so, this cannot completely explain the high concentration of pol- $^{-980}$ lutants there. The sections of Sallanches and Marnaz emit a similar amount of pollution during the episode, although in Sallanches there is a much higher concen-981 tration of $\mathrm{PM}_{10}$ than in Marnaz. As well, this differ- ${ }_{982}$ ence cannot be explained only from the point of view ${ }_{983}$ of emissions, rising the need to estimate the ventila- ${ }_{984}$ tion potential in the domain.

- Following the method developed by Allwine and Whiteman (1994), zones prone to ventilation and stagnation ${ }^{987}$ in the domain were characterized (see Fig. 13). A re- ${ }^{988}$ lationship was identified between these zones, their re- ${ }^{989}$ spective emission sources and the zones liable to high $^{900}$ pollution. In Passy, for example, critical stagnation ${ }^{91}$ is often found due to the fact that it remains decou-9 ${ }^{92}$ pled from the rest of the central part of the Passy val- $-^{903}$ ley. The air from the Chamonix and St-Gervais trib-994 utaries indeed detach over the bottom layer in Passy, ${ }^{905}$ with the major part of the mass flux flowing over that ${ }^{96}$ layer and leaving it unperturbed. Only a small fraction ${ }^{97}$ of that flux contributes to the $\mathrm{PM}_{10}$ concentration in ${ }^{98}$ the Passy section, about $15 \%$ over the episode. On the ${ }^{999}$ other hand, the air from Megève can flow into the CAP but goes down-valley towards Sallanches, leaving the section in Passy uncoupled from the rest of the valley, which creates a stagnation zone. Such stagnation zonfoor along with the fact that this area presents the highestoos emission of all the valley sections, results in the highpos concentration of $\mathrm{PM}_{10}$ recorded in the area. $\quad 1005$

- The local and non-local contribution to the concenioor tration of $\mathrm{PM}_{10}$ in the different sections of the valley has been identified. In Passy, which through the anal-0o9 ysis stands out as the location with the highest emis ${ }_{1011}$ sions, showing the greatest problems of atmospherico12 stagnation and particulate air pollution, the most important factor contributing to the pollution reported at the AQS site was the local sources. The decoupled character of the area and the large emissions become a dangerous combination. In Sallanches, on the other hand, the impact of external sources (such as tributaries and Passy's pollution) play an important role in the problem by reporting a very similar contribution to local sources. From this study, it is clear that there is almost no transport in the upstream direction through the episode. Indeed no section of the valley seems to be affected by pollution released in a neighbouring downstream section suggesting no up-valley transport during the episode.

As a final consideration, it is important to note that the analysis presented in this paper is based entirely on a single winter and especially on a one-week pollution episode. Although the results of the Passy-15 field campaign and the works exploring those results (including the one presented here) provide valuable information on the drivers of particulate air pollution in the valley, the need for long-term meteorological and pollutant measurements in the area to better understand what is leading to such pollution problems is clear.

\section{Acknowledgements}

The PhD work of J. Quimbayo is supported by the Colombian Administrative Department of Science, Technology and Innovation (COLCIENCIAS). Numerical simulations were run on the ARCHER UK National Supercomputing Service (http://www.archer.ac.uk). The Passy-2015 field experiment was supported by ADEME through the French national programme LEFE/INSU and by METEO-FRANCE. We thank the cities of Passy and Sallanches for their kind support. The field experiment was led by CNRM while the LEGI laboratory was the principal investigator of the LEFE/INSU project. The rawingsonde data used in Fig. 4 are managed by SEDOO at Observatoire Midi-Pyrénées. We thank the people involved in the launching of the rawingsonde and data acquisition therefrom. Finally, we thank the local airquality Agency Atmo Auvergne-Rhône-Alpes for supplying the emission inventory in which the emission input for the numerical simulations is based, and the valuable comments on the present work.

\section{References}

K. J. Allwine and C. D. Whiteman. Single-station integral measures of atmospheric stagnation, recirculation and ventilation. Atmospheric Environment, 28(4):713-721, 1994.

J. O. Anderson, J. G. Thundiyil, and A. Stolbach. Clearing the air: a review of the effects of particulate matter air pollution on human health. Journal of Medical Toxicology, 8(2):166-175, 2012.

G. Arduini, C. Chemel, and C. Staquet. Local and non-local controls on a persistent cold-air pool in the arve river valley. Quarterly Journal of the Royal Meteorological Society, 2020.

Atmo-Auvergne-Rhône-Alpes. Méthode d'élaboration de l'inventaire des émissions atmosphériques en auvergne-rhône-alpes. Technical report, Atmo-Auvergne-Rhône-Alpes, 2017. 
Atmo-Auvergne-Rhône-Alpes. Bilan des connaissances sur la qualité dero81 l'air dans la vallée de l'arve. Technical report, Atmo-Auvergne-Rhône-osz Alpes, 2018.

1083

G. Aymoz, J. L. Jaffrezo, D. Chapuis, J. Cozic, and W. Maenhaut. Searosa sonal variation of $\mathrm{pm}_{10}$ main constituents in two valleys of the frenctoss alps. i: Ec/oc fractions. Atmospheric Chemistry and Physics, 7(3).086 661-675, 2007. doi: 10.5194/acp-7-661-2007. URL https://www1087 atmos-chem-phys. net/7/661/2007/.

1088

M. Baasandorj, S. W. Hoch, R. Bares, J. C. Lin, S. S. Brown, D. B. Milletosg R. Martin, K. Kelly, K. J. Zarzana, C. D. Whiteman, et al. Couplingsoo between chemical and meteorological processes under persistent coldog1 air pool conditions: Evolution of wintertime pm2. 5 pollution eventrog2 and n2o5 observations in utah's salt lake valley. Environmental Sciencro93 \& Technology, 51(11):5941-5950, 2017.

P. Chazette, P. Couvert, H. Randriamiarisoa, J. Sanak, B. Bonsangog5 P. Moral, S. Berthier, S. Salanave, and F. Toussaint. Three-dimensionab96 survey of pollution during winter in french alps valleys. AE, 39(6): 1035¥097 1047, 2005.

C. Chemel, G. Arduini, C. Staquet, Y. Largeron, D. Legain, D. Tzanos, anrbg9 A. Paci. Valley heat deficit as a bulk measure of wintertime particulateroo air pollution in the arve river valley. Atmos. Environ., 128:208-215,101 2016.

1102

F. Chen and J. Dudhia. Coupling an advanced land surface-hydrologyio3 model with the penn state-ncar mm5 modeling system. part i: Modaho4 implementation and sensitivity. Mon. Weather. Rev., 129(4):569-585,105 2001.

1106

F. Chevrier. Chauffage au bois et qualité de l'air en Vallée de l'Arve : défi-107 nition d'un système de surveillance et impact d'une politique de rénova-108 tion du parc des appareils anciens. $\mathrm{PhD}$ thesis, Université de Chambéry,109 France, 2016.

1110

F. K. Chow, A. P. Weigel, R. L. Street, M. W. Rotach, and M. Xue. High-11 resolution large-eddy simulations of flow in a steep alpine valley. panti12 i: Methodology, verification, and sensitivity experiments. Journal afi13 Applied Meteorology and Climatology, 45(1):63-86, 2006.

T. Cook, K. Wastrack, and D. Pittman. Identifying non-linear flow for mod-115 eling of routine releases from tva nuclear facilities. Technical report116 Tennessee Valley Authority (internal report), 2011.

1117

A. De Meij and J. Vinuesa. Impact of srtm and corine land cover data on18 meteorological parameters using wrf. Atmospheric research, 143:351 $1 \mathbf{1 1 9}$ 370, 2014

1120

T. G. Farr, P. A. Rosen, E. Caro, R. Crippen, R. Duren, S. Hensley, M. Ka-121 brick, M. Paller, E. Rodriguez, L. Roth, et al. The shuttle radar topogras22 phy mission. Rev. Geophys., 45(2), 2007.

1123

C. Foster, E. Crosman, and J. Horel. Simulations of a cold-air pool in utah's24 salt lake valley: Sensitivity to land use and snow cover. Boundary-Layen125 Meteorology, 164(3):63-87, 2017.

A. Gohm, F. Harnisch, J. Vergeiner, F. Obleitner, R. Schnitzhofer,127 A. Hansel, A. Fix, B. Neininger, S. Emeis, and K. Schäfer. Air pollutionn 28 transport in an alpine valley: Results from airborne and ground-baserh 29 observations. Boundary-layer meteorology, 131(3):441-463, 2009. 1130

M. C. Green, J. C. Chow, J. G. Watson, K. Dick, and D. Inouye. Effects afiz1 snow cover and atmospheric stability on winter pm2. 5 concentrationrs 32 in western us valleys. J. Appl. Meteorol. Climatol., 54(6):1191-120 h,133 2015.

1134

M. Guxens, R. Garcia-Esteban, and L. e. a. Giorgie-Allemand. Air pollu-135 tion during pregnancy and childhood cognitive and psychomotor devel-136 opment: Six european birth cohorts. Epidemiology, 25:636-647, 2014L137

S.-Y. Hong. A new stable boundary-layer mixing scheme and its impact onı38 the simulated east asian summer monsoon. Q. J. R. Meteorol. Soc., $13 f_{139}$ (651):1481-1496, 2010.

1140

P. A. Jiménez, J. Dudhia, J. F. González-Rouco, J. Navarro, J. P. Montávez141 and E. García-Bustamante. A revised scheme for the wrf surface layer formulation. Mon. Weather. Rev., 140(3):898-918, 2012.

Y. Largeron. Dynamique de la Couche Limite Atmosphérique Stable en relief complexe. Application aux épisodes de pollution particulaire des vallées alpines. $\mathrm{PhD}$ thesis, Université de Grenoble, 2010.

Y. Largeron and C. Staquet. Persistent inversion dynamics and wintertime $\mathrm{pm}_{10}$ air pollution in alpine valleys. Atmos. Environ., 135:92-108, 2016.
E. J. Mlawer, S. J. Taubman, P. D. Brown, M. J. Iacono, and S. A. Clough. Radiative transfer for inhomogeneous atmospheres: RRTM, a validated correlated-k model for the longwave. J. Geophys. Res., 102:663-682, 1997.

H. Morrison, J. Curry, and V. Khvorostyanov. A new double-moment microphysics parameterization for application in cloud and climate models. part i: Description. J. Atmos. Sci., 62(6):1665-1677, 2005.

V. Nair, S. Babu, M. Manoj, K. Moorthy, and C. M. Direct radiative effects of aerosols over south asia from observations and modeling. Climate Dynamics, 49:1411-1428, 2017.

E. Neemann, E. Crosman, J. Horel, and L. Avey. Simulations of a cold-air pool associated with elevated wintertime ozone in the uintah basin, utah. Atmos. Chem. Phys., 15(1), 2015.

A. Paci, C. Staquet, J. Allard, H. Barral, G. Canut, J.-M. Cohard, J.-L. Jaffrezo, P. Martinet, T. Sabattier, F. Troude, et al. La campagne passy2015: dynamique atmosphérique et qualité de l'air dans la vallée de l'arve. 2268-3798, 2017.

C. Piot. Polluants atmosphériques organiques particulaires en RhôneAlpes: caractérisation chimique et sources d'émissions. $\mathrm{PhD}$ thesis, Université de Grenoble, 2011.

A. Rasheed, D. Robinson, A. Clappier, C. Narayanan, and D. Lakehal. Representing complex urban geometries in mesoscale modeling. International Journal of Climatology, 31(2):289-301, 2011.

A. M. Rendón, J. F. Salazar, C. A. Palacio, V. Wirth, and B. Brötz. Effects of urbanization on the temperature inversion breakup in a mountain valley with implications for air quality. J. Appl. Meteorol. Climatol., 53(4): 840-858, 2014.

T. Sabatier, A. Paci, G. Canut, Y. Largeron, A. Dabas, J.-M. Donier, and T. Douffet. Wintertime local wind dynamics from scanning doppler lidar and air quality in the arve river valley. Atmosphere, 9(4):118, 2018.

M. Schaap, M. Roemer, F. Sauter, G. Boersen, R. Timmermans, P. Builtjes, and A. Vermeulen. Lotos-euros: Documentation. TNO report, 297, 2005.

G. D. Silcox, K. E. Kelly, E. T. Crosman, C. D. Whiteman, and B. L. Allen. Wintertime pm 2.5 concentrations during persistent, multi-day cold-air pools in a mountain valley. Atmos. Environ., 46:17-24, 2012.

W. C. Skamarock, J. B. Klemp, J. Dudhia, D. O. Gill, D. M. Barker, M. G. Duda, X.-Y. Huang, W. Wang, and J. G. Powers. A description of the advanced research wrf version 3. Technical report, National Center For Atmospheric Research Boulder Co Mesoscale and Microscale Meteorology Div, 2005.

S. Smith, F. T. Stribley, P. Milligan, and B. Barratt. Factors influencing measurements of pm10 during 1995-1997 in london. Atmos. Environ., 35(27):4651-4662, 2001

C. Staquet, A. Paci, and J. Allard. The passy project: objectives, underlying scientific questions and preliminary numerical modeling of the passy alpine valley. Proc. of the 33rd International on Alpine Meteorology, Innsbruck, Austria, 2015.

E. Tomasi, L. Giovannini, D. Zardi, and M. de Franceschi. High-resolution numerical simulations of wintertime atmospheric boundary layer processes in the adige valley during an alpnap project field campaign. In EGU General Assembly Conference Abstracts, volume 16, 2014.

S. Vardoulakis and P. Kassomenos. Sources and factors affecting pm10 levels in two european cities: Implications for local air quality management. Atmos. Environ., 42(17):3949-3963, 2008.

J. Wagner, N. Wildmann, and T. Gerz. Improving boundary layer flow simulations over complex terrain by applying a forest parameterization in wrf. Wind Energy Science, 2019.

C. D. Whiteman, S. W. Hoch, J. D. Horel, and A. Charland. Relationship between particulate air pollution and meteorological variables in utah's salt lake valley. Atmos. Environ., 94:742-753, 2014. 